Review

\title{
Review of Propulsion System Design Strategies for Unmanned Aerial Vehicles
}

\author{
Cinzia Amici ${ }^{1}$ (D) Federico Ceresoli ${ }^{1}$, Marco Pasetti ${ }^{2}\left(\mathbb{D}\right.$, Matteo Saponi $^{3}$, Monica Tiboni ${ }^{1, *(D)}$ and \\ Simone Zanoni ${ }^{4}$ (D) \\ 1 Department of Mechanical and Industrial Engineering, University of Brescia, Via Branze, 38, \\ 25123 Brescia, Italy; cinzia.amici@unibs.it (C.A.); f.ceresoli002@unibs.it (F.C.) \\ 2 Department of Information Engineering, University of Brescia, Via Branze, 38, 25123 Brescia, Italy; \\ marco.pasetti@unibs.it \\ 3 Imbal Carton s.r.l., Via Gardesana, 54, 25080 Prevalle, Italy; m.saponi@imbalcarton.com \\ 4 Department of Civil, Environmental, Architectural Engineering and Mathematics, University of Brescia, \\ Via Branze, 43, 25123 Brescia, Italy; simone.zanoni@unibs.it \\ * Correspondence: monica.tiboni@unibs.it
}

check for updates

Citation: Amici, C.; Ceresoli, F.; Pasetti, M.; Saponi, M.; Tiboni, M.; Zanoni, S. Review of Propulsion System Design Strategies for Unmanned Aerial Vehicles. Appl. Sci. 2021, 11, 5209. https://doi.org/ 10.3390/app11115209

Academic Editors: Alberto Doria Silvio Cocuzza and Benedetto Allotta

Received: 15 March 2021

Accepted: 31 May 2021

Published: 4 June 2021

Publisher's Note: MDPI stays neutral with regard to jurisdictional claims in published maps and institutional affiliations.

Copyright: (c) 2021 by the authors. Licensee MDPI, Basel, Switzerland. This article is an open access article distributed under the terms and conditions of the Creative Commons Attribution (CC BY) license (https:/ / creativecommons.org/licenses/by/ $4.0 /)$.

\begin{abstract}
The design of the propulsion system for Unmanned Aerial Vehicles (UAVs) demands an inclusive multidisciplinary approach from the earliest design phases, since every design choice strictly affects and is affected by the overall working conditions. This paper presents a review of the scientific literature focused on the design methods applied in defining and sizing the propulsion system of drones. The analysis, performed with a systematic approach, evaluated 123 papers according to two custom classification taxonomies, which investigated respectively the primary aim and specific content of the works. Finally, literature indications and hints were combined into an integrated framework for the functional design of the propulsion system of UAVs. The procedure aimed to support the designer in the preliminary selection of the propulsion candidates and the quick sizing of the supply system, during the first phases of the design process. According to the literature, design methods dramatically change depending on the expected applications and working conditions of UAVs, so that the detailed design of specific drone elements and propulsion components represents the focus of most of the papers in this field.
\end{abstract}

Keywords: propulsion system; Unmanned Aerial Vehicles (UAVs); energy consumption; power supply system; actuators' characterization; design process; selection problem

\section{Introduction}

In recent years, the use of drones has spread to applications such as monitoring activities or delivery tasks and last-mile logistics. According to Drone Industry Insights, the global drone market in 2020 generated about 22 billion USD, and it is expected to grow at a Compound Annual Growth Rate (CAGR) of $13.8 \%$ to reach 42.8 billion USD by 2025. Total investment in 2019 was about 1.2 billion USD, $+67 \%$ with respect to 2018 [1]. According to this, the attention of industrial and scientific communities towards drones' design and optimization processes has rapidly increased.

Many drone classifications can be found in the literature, based on different parameters, such as specific architectures and missions [2,3]. For instance, considering mass and wingspan, a taxonomy that identifies six classes can be defined, as reported in Table 1 [2]. According to this classification, drones present very distinct physical characteristics even within the Unmanned Aerial Vehicles (UAVs) class and are therefore characterized by very different configurations, both in terms of structures and elements dedicated to propulsion. 
Table 1. Example of drone classifications based on mass and wingspan, from Smart Dust (SD) to Unmanned Air Vehicles (UAVs): PAVs, Pico Aerial Vehicles; NAVs, Nano Aerial Vehicles; MAVs, Micro Aerial Vehicles; $\mu \mathrm{UAVs}$, micro Unmanned Aerial Vehicles.

\begin{tabular}{ccc}
\hline Drone Size Class & Mass & Wingspan \\
\hline SDs & $0.5 \mathrm{~g}-0.005 \mathrm{~g}$ & $1 \mathrm{~mm}-2.5 \mathrm{~mm}$ \\
PAVs & $0.5 \mathrm{~g}-3 \mathrm{~g}$ & $2.5 \mathrm{~mm}-25 \mathrm{~mm}$ \\
NAVs & $3 \mathrm{~g}-50 \mathrm{~g}$ & $25 \mathrm{~mm}-250 \mathrm{~mm}$ \\
MAVs & $50 \mathrm{~g}-2 \mathrm{~kg}$ & $250 \mathrm{~mm}-1 \mathrm{~m}$ \\
$\mu \mathrm{UAVs}$ & $2 \mathrm{~kg}-5 \mathrm{~kg}$ & $1 \mathrm{~m}-2 \mathrm{~m}$ \\
UAVs & $5 \mathrm{~kg}-15,000 \mathrm{~kg}$ & $2 \mathrm{~m}-61 \mathrm{~m}$ \\
\hline
\end{tabular}

UAVs represent complex systems, integrating various kinds of elements within a single body-frame; arranging them into consistent sub-systems, such as the aerodynamic components, propulsion system, or control architecture, is generally the first step of the design process. According to the literature, the propulsion system is the main element of each unmanned platform [4] and has the highest priority among the design requirements [5]. The propulsion system can constitute a significant part of the UAV mass (in some cases, more than half [6]). It generates the mechanical power necessary for the operations of the drone, but also contributes to energy consumption; therefore, its performance significantly affects the performance and autonomy of the UAV. For these reasons, the design of the propulsion system in UAV applications, from its conceiving and sizing phases to the detailed design, presents almost unique characteristics, given the need for an inclusive multidisciplinary approach from the first design stages.

The literature depicts a few examples of design sizing and optimization for UAVs' propulsion systems, and these methods are often dedicated to specific drone typologies or power supply types [5,7-10]. For smaller UAVs within their class, a formalization of the procedure leading to the choice of the propulsion group is not even present in the literature, to date. Since the heterogeneous nature of possible application cases and working conditions strongly affects the design framework, a review of the scientific literature needs to be performed to properly outline the current state-of-the-art for the design of UAVs' propulsion systems.

Within this context, this paper aimed to provide a comprehensive overview of the possible propulsion system design strategies, investigating frameworks and application examples currently available in the literature. The review analysis was performed with a systematic approach, and the results were evaluated in light of a dual custom classification taxonomy, which investigated the primary purpose of each work and specific contents. Then, literature indications and hints were combined into an integrated framework for the functional design of the propulsion systems of UAVs. The proposed method aimed at representing a support to the designer in the first phases of the design process, offering a preliminary selection strategy for the propulsion candidates and a quick sizing method for the supply system, which allows discarding unsuitable components from the early stages of the optimization process.

The paper is organized as follows: Section 2 describes the approach and procedures applied to perform the paper selection, as well as the evaluation criteria selected for the results' analysis, with particular attention to the design requirements. Section 3 reports the main outcomes of the literature analysis, gathering the obtained values for the most significant design parameters, and introduces the outline of the proposed integrated functional design framework. The data, as well as strength and limits of this framework are then analyzed in Section 4, and finally, Section 5 synthesizes the salient results of the work.

\section{Materials and Methods}

The Scopus database was considered for the analysis, investigating the words design and propulsion/actuator/motor and possible variations in the title, combined with the 
words UAV, or unmanned and aerial/vehicle, or drone and variations of the title, abstract, and keywords. The final search string (TITLE(design) AND TITLE((propuls* OR actuat* OR motor*)) AND TITLE-ABS-KEY((uav OR (unmanned AND aerial AND vehicl*) OR dron*))) was used. The query, updated at the latest on 14 May 2021, identified 146 results. Among them, only those in the English language were considered; seven works were therefore excluded. No further exclusion criteria were applied.

The remaining 139 results were then analyzed, investigating the aim and content of the manuscripts. Sixteen papers were further excluded as outside of the topic, and one-hundred twenty-three works were then considered as the final set of selected papers.

\section{Data Analysis}

The 123 papers were categorized according to the first taxonomy, which focused on the main purpose of the work. This classification involved the following categories:

- functional design, sizing;

- optimization methods;

- controls, identification, modeling;

- detailed design.

The first category collected the papers depicting design methods for the identification of the functional characteristics of a drone or sizing procedures for the propulsion system from a methodological perspective. Papers describing the code and strategies for the definition of optimal solutions for specific viewpoints were gathered in the optimization methods group. The third category collected papers concerning control systems, parameter identification methods, or the modeling of already selected or existing devices. Papers focusing on the study of specific aspects or components of the drone were finally included in the detailed design category.

For the current purposes, the works classified within the functional design and sizing group were analyzed specifically to capture which kinds of requirements were evaluated along the design process. Those requirements were arranged into three main sets:

- technical constraints;

- normative framework-related limits;

- custom requirements.

For the technical group, a further distinction was made among constraints related to drone Geometry (G), Dynamics (D), Power Supply (PS), and Mission Requirements (MRs).

All 123 papers were then assessed according to the second taxonomy, which analyzed the content of the works. Four main aspects were investigated:

(i) UAV type;

(ii) actuation type;

(iii) design level;

(iv) topics.

The first class evaluated the type of UAVs explicitly considered by the authors as the main target of their work. In particular, four sub-categories were identified: FixedWing vehicles (FxWs), Flapping-Wing drones (FlWs), Multirotors (Mrs), and Other kinds of UAVs $(\mathrm{O})$. The class actuation type focused on the propulsion strategy that the UAV presented. More in detail, the following sub-categories were considered: Fuel (F), Electric (E), Hybrid $(\mathrm{H})$, and other. The third class evaluated the level of detail considered by the described design framework. Three main sub-categories were defined: Vehicle (Ve), Propulsion System (PrS), and Propulsion Component $(\operatorname{PrC})$. For the latter, the distinction among components was also performed, considering the entries: Motor (Mo), Propeller (Pl), Batteries (B), and other. Finally, the class topics investigated the macro-areas involved in the design framework proposed by the specific work. For this analysis, the following subcategories were defined: kinematics, dynamics (also meant as aero- and fluid-dynamics), Mechanics (Me), power supply, Mission Planning (MP), Optimization (Op), Validation (Va), Fault Management (FM), and Control (C). 


\section{Results}

\subsection{Literature Analysis}

Figures 1 and 2 depict the distribution of the papers among the proposed categories and their numerical evolution in time, respectively, in aggregate form.

\section{Literature Overview}

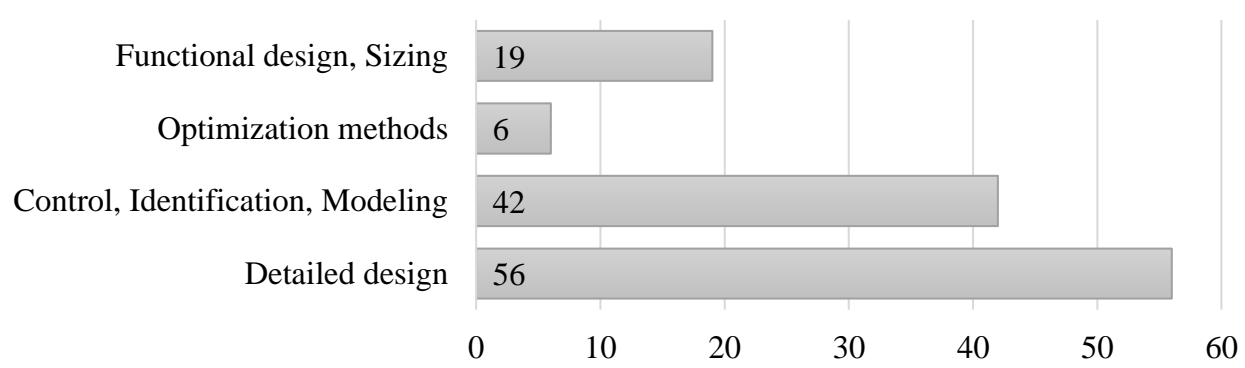

Figure 1. Distribution of the analyzed papers among the identified categories according to the proposed classification.

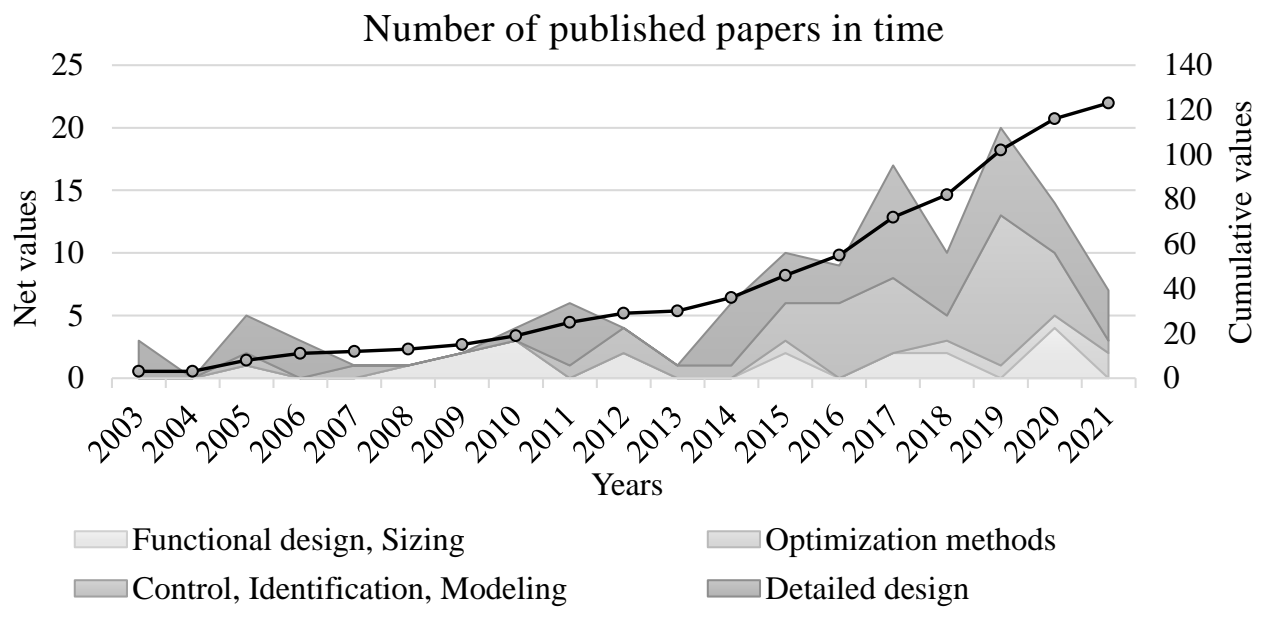

Figure 2. For each category, the number of published papers over time is plotted in stacked style. In the black line, the cumulative function.

For the papers categorized within the functional design, sizing category, Table 2 synthesizes the results of the requirements' assessment. 
Table 2. Classification of the constraints analyzed in each paper within the functional design, sizing category, among technical, normative, and custom sets. For the technical constraints, the distinction among the four subsets of Geometry (G), Dynamics (D), Power Supply (PS), and Mission Requirements (MRs) is reported.

\begin{tabular}{|c|c|c|c|c|c|c|}
\hline \multirow{2}{*}{ Paper } & \multicolumn{4}{|c|}{ Technical } & \multirow{2}{*}{ Normative } & \multirow{2}{*}{ Custom } \\
\hline & G & D & PS & MRs & & \\
\hline Dantsker 2020 [11] & $x$ & $x$ & $x$ & $\mathrm{x}$ & & \\
\hline Hossain 2020 [12] & $\mathrm{x}$ & $x$ & & & & \\
\hline Saemi * 2020 [13] & $x$ & $x$ & $x$ & $x$ & & \\
\hline Siswoyo Jo 2020 [14] & $x$ & $x$ & $x$ & $x$ & & \\
\hline Guo 2018 [15] & $x$ & $x$ & & $x$ & & \\
\hline Zhao 2018 [10] & $x$ & $x$ & $x$ & & $x^{1}$ & \\
\hline Castaneda 2017 [16] & & $x$ & $x$ & & & \\
\hline Kotarski 2017 [17] & $x$ & $x$ & & $x$ & & \\
\hline Bershadsky 2015 [9] & $\mathrm{x}$ & $\mathrm{x}$ & $\mathrm{x}$ & $\mathrm{x}$ & & \\
\hline Heim 2015 [18] & $x$ & $x$ & & $x$ & & \\
\hline Li 2012 [19] & $x$ & $x$ & $x$ & $x$ & & $\mathrm{x}^{I}$ \\
\hline Lindahl 2012 [20] & & $x$ & $x$ & & & \\
\hline Aksugur 2010 [5] & $x$ & $x$ & $x$ & $x$ & & $\mathrm{x}^{I I}$ \\
\hline Capata 2010 [21] & & $x$ & $x$ & $x$ & & \\
\hline Hiserote 2010 [22] & $x$ & $\mathrm{x}$ & $x$ & $\mathrm{x}$ & $x^{2}$ & \\
\hline Lindahl 2009 [23] & & $x$ & $x$ & $x$ & & \\
\hline Stepaniak 2009 [24] & & $x$ & $x$ & $x$ & & \\
\hline Aksugur 2008 [8] & $x$ & $x$ & $x$ & $x$ & $x^{1}$ & \\
\hline Soban 2005 [25] & $x$ & $x$ & $x$ & $x$ & & \\
\hline
\end{tabular}

Legend: G, Geometry; D, Dynamics; PS, Power Supply; MRs, Mission Requirements. Notes: $\mathrm{x}^{1}$ Mission Requirements: operating altitude. $x^{2}$ Aircraft size restricted to the Group 2 (small) UAS category: maximum gross mass. At take-off of 21 to $55 \mathrm{lbs}$, normal operating altitude below 3500 feet AGL. $x^{I}$ Logistics and loitering missions requiring no more than 4 people, usable by non-professional operators. $\mathrm{x}^{I I}$ Limited maintenance, limited noise. * Data from paper abstract (full-text not available).

Tables 3-11 collect the results of the literature analysis, according to the taxonomy, which focuses on the papers' content. In those tables, data are presented by category and sorted by year (from newest to oldest) and, within each year, by the first author's surname (in alphabetic order), whereas Table 12 synthesizes all the results of the literature review at a glance. 
Table 3. Evaluation of the papers categorized in the functional design, sizing category, according to the taxonomy referring to the paper content.

\begin{tabular}{|c|c|c|c|c|c|c|c|c|c|c|c|c|c|c|c|c|c|c|c|c|c|c|c|}
\hline \multirow{3}{*}{ Paper } & \multicolumn{4}{|c|}{ UAV Type } & \multicolumn{4}{|c|}{ Actuation Type } & \multicolumn{6}{|c|}{ Design Level } & \multicolumn{9}{|c|}{ Topics } \\
\hline & \multirow{2}{*}{ FxW } & \multirow{2}{*}{ FlW } & \multirow{2}{*}{ Mr } & \multirow{2}{*}{$\mathbf{O}$} & \multirow{2}{*}{$\mathbf{F}$} & \multirow{2}{*}{$\mathrm{E}$} & \multirow{2}{*}{$\mathbf{H}$} & \multirow{2}{*}{$\mathbf{O}$} & \multirow{2}{*}{ Ve } & \multirow{2}{*}{ PrS } & \multicolumn{4}{|c|}{ PrC } & \multirow{2}{*}{$\mathbf{K}$} & \multirow{2}{*}{ D } & \multirow{2}{*}{ Me } & \multirow{2}{*}{ PS } & \multirow{2}{*}{ MP } & \multirow{2}{*}{ Op } & \multirow{2}{*}{ Va } & \multirow{2}{*}{ FM } & \multirow{2}{*}{$\mathrm{C}$} \\
\hline & & & & & & & & & & & Mo & P1 & B & $\mathbf{O}$ & & & & & & & & & \\
\hline Dantsker 2020 [11] & $x$ & & & & & $x$ & & & & $x$ & & & & & & & & $x$ & & $x$ & $x$ & & \\
\hline Hossain 2020 [12] & $x$ & & & $x^{1}$ & & & & & & & & & & $x^{2}$ & & & $x$ & & & & & & \\
\hline Saemi 2020 [13] & & & & & & $x$ & & & & & & & & & & $x$ & $x$ & $x$ & & & $x$ & & \\
\hline Siswoyo Jo 2020 [14] & & & $x$ & & & & & & $x$ & $x$ & & & & & & $x$ & $x$ & $x$ & & & $x$ & & $x$ \\
\hline Guo 2018 [15] & $x$ & & & & & & & & & $x$ & & & & & & $x$ & $x$ & & & $\mathrm{x}$ & $x$ & & \\
\hline Zhao 2018 [10] & $x$ & & & & & $x$ & & & & $x$ & & & & & & $x$ & & $x$ & & & $x$ & & $x$ \\
\hline Castaneda 2017 [16] & & & $x$ & & & $x$ & & & & $x$ & & & & & & & $x$ & $x$ & & & $x$ & & $\mathrm{x}$ \\
\hline Kotarski 2017 [17] & & & $x$ & & & & & & & & & & & & & $x$ & $x$ & & & & $x$ & & $\mathrm{x}$ \\
\hline Bershadsky 2015 [9] & & & $x$ & & & $x$ & & & & $x$ & & & & & & & $x$ & & $x$ & & $x$ & & \\
\hline Heim 2015 [18] & & & & & & & & & & & & & & $x^{3}$ & & $x$ & $x$ & & & $x$ & $x$ & & \\
\hline Li 2012 [19] & $x$ & & & & & $x$ & & & $x$ & & & & & & & & $x$ & $x$ & & & $x$ & & \\
\hline Lindahl 2012 [20] & $x$ & & & & & $x$ & & & & $x$ & & & & & & $x$ & $x$ & $x$ & & & $x$ & & $x$ \\
\hline Aksugur 2010 [5] & $x$ & & & & & & $x$ & & & & & & & & & & $x$ & & & $x$ & & & \\
\hline Lindahl 2009 [23] & $x$ & & & & & & $x$ & & & $x$ & & & & & & & $x$ & $x$ & & & $x$ & & \\
\hline Stepaniak 2009 [24] & & & $x$ & & & $x$ & & & $x$ & & & & & & & $x$ & $x$ & $x$ & $x$ & & $x$ & & $\mathrm{x}$ \\
\hline Aksugur 2008 [8] & $x$ & & & & & & $x$ & & & $x$ & & & & & & $x$ & $x$ & & & & & & \\
\hline Soban 2005 [25] & $x$ & & & & & $x$ & & & $x$ & & & & & & & & & & $x$ & & & & \\
\hline
\end{tabular}

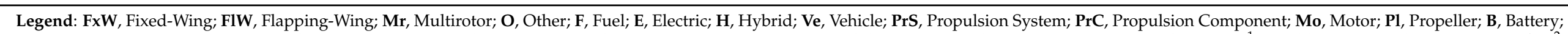

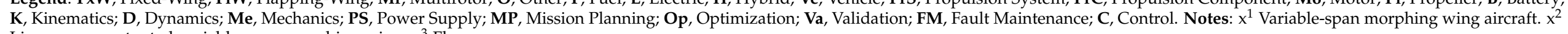
Linear servo-actuated variable-span morphing wing. $x^{3}$ Flap. 
Table 4. Evaluation of the papers categorized in the optimization methods, according to the taxonomy referring to the paper content.

\begin{tabular}{|c|c|c|c|c|c|c|c|c|c|c|c|c|c|c|c|c|c|c|c|c|c|c|c|}
\hline \multirow{3}{*}{ Paper } & \multicolumn{4}{|c|}{ UAV Type } & \multicolumn{4}{|c|}{ Actuation Type } & \multicolumn{6}{|c|}{ Design Level } & \multicolumn{9}{|c|}{ Topics } \\
\hline & \multirow{2}{*}{ FxW } & \multirow{2}{*}{ FlW } & \multirow{2}{*}{ Mr } & \multirow{2}{*}{$\mathbf{O}$} & \multirow{2}{*}{$\mathbf{F}$} & \multirow{2}{*}{$\mathbf{E}$} & \multirow{2}{*}{$\mathbf{H}$} & \multirow{2}{*}{$\mathbf{O}$} & \multirow{2}{*}{ Ve } & \multirow{2}{*}{ PrS } & \multicolumn{4}{|c|}{ PrC } & \multirow{2}{*}{$\mathbf{K}$} & \multirow{2}{*}{ D } & \multirow{2}{*}{ Me } & \multirow{2}{*}{ PS } & \multirow{2}{*}{ MP } & \multirow{2}{*}{ Op } & \multirow{2}{*}{ Va } & \multirow{2}{*}{ FM } & \multirow{2}{*}{ C } \\
\hline & & & & & & & & & & & Mo & P1 & B & $\mathbf{O}$ & & & & & & & & & \\
\hline Ahn 2021 [26] & & & & & & $x$ & & & & & & & & & & $x$ & & & & $x$ & $x$ & & \\
\hline Zhang 2021 [27] & & & & $x^{1}$ & & $x$ & & & & $x$ & & & & & & $x$ & $x$ & $x$ & $x$ & $x$ & $x$ & & \\
\hline LI 2020 [7] & $x$ & & & & & & & & $x$ & $x$ & & & & & & $x$ & $x$ & $x$ & $x$ & $x$ & & & \\
\hline Thilakraj 2019 [28] & & & & $x^{2}$ & $x$ & & & & & & & $\mathrm{x}$ & & & & $x$ & $x$ & & & & $x$ & & \\
\hline $\begin{array}{l}\text { Yazdani-Asrami } \\
2015 \text { [30] }\end{array}$ & & & & & & $x$ & & & & & $x$ & & & & & & $x$ & $x$ & & $x$ & & & \\
\hline Ullah 2021 [31] & & & $x$ & & & & & & $x$ & & & & & $x^{3}$ & & & & $x$ & $x$ & & $x$ & & $x$ \\
\hline
\end{tabular}


Table 5. Evaluation of the papers categorized in the controls, identification, modeling category from 2019, according to the taxonomy referring to the paper content.

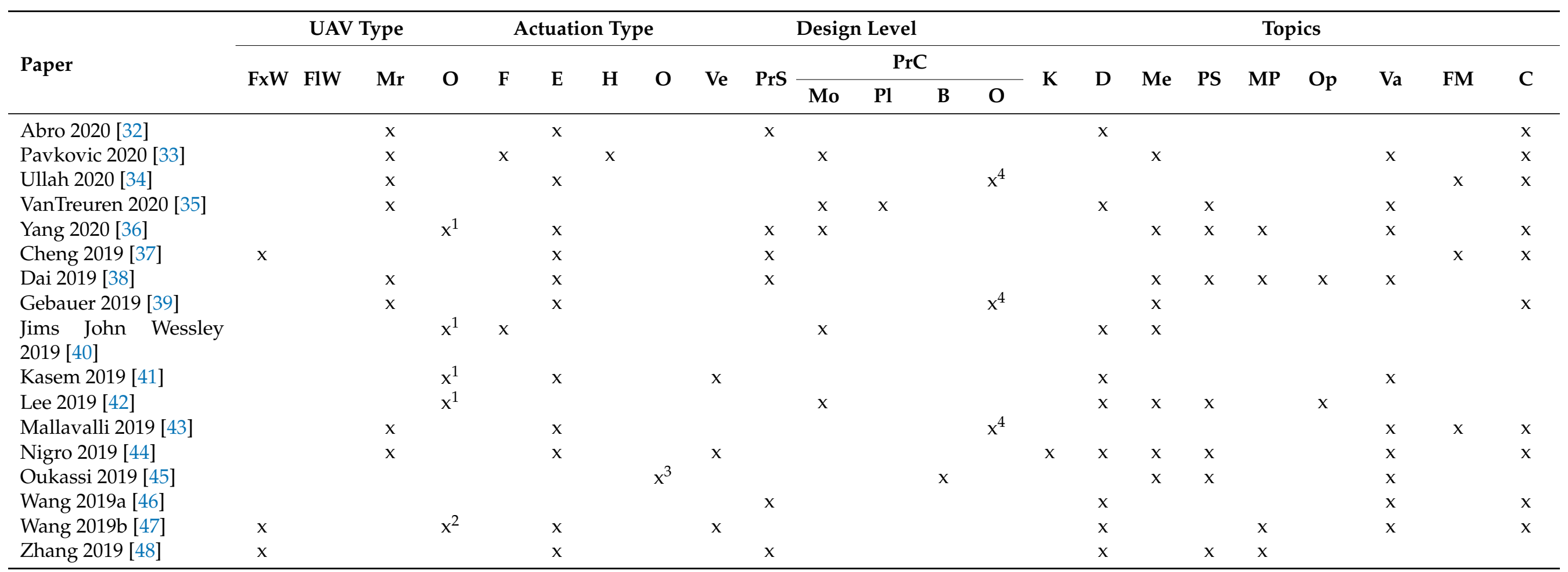

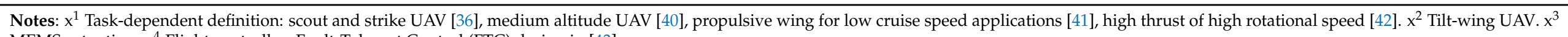
MEMS actuation. $x^{4}$ Flight controller: Fault-Tolerant Control (FTC) design in [43]. 
Table 6. Evaluation of the papers categorized in the controls, identification, modeling category from 2016 to 2018 , according to the taxonomy referring to the paper content.

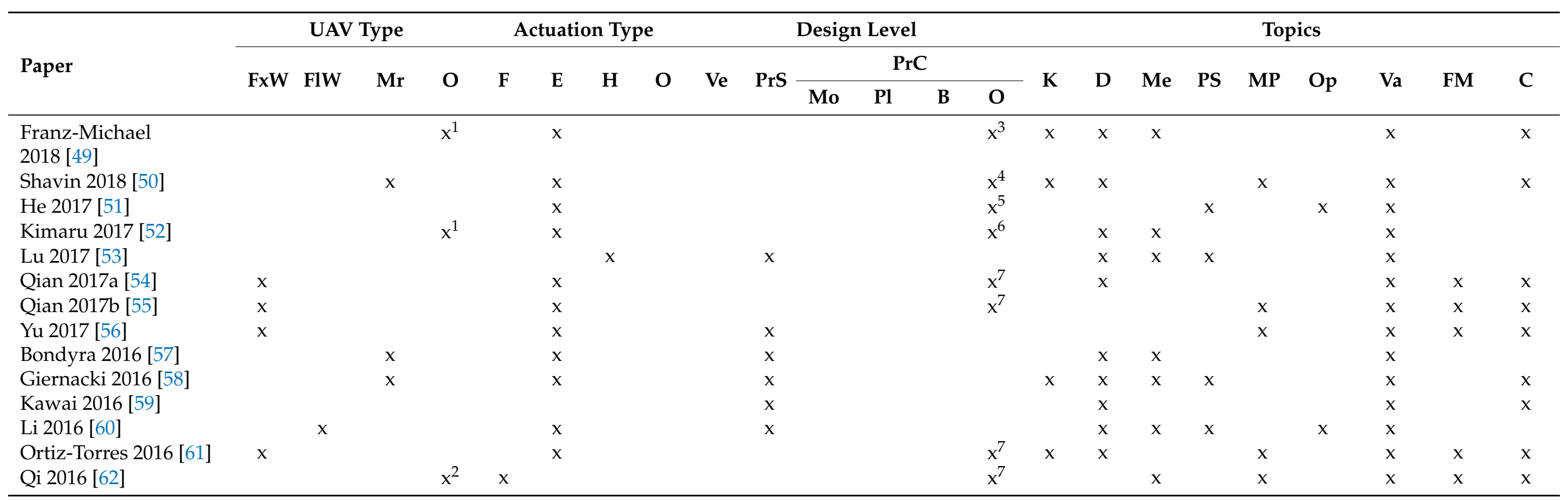

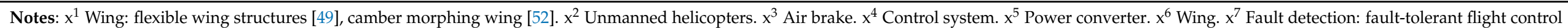
Notes: $x^{1}$ Wing: flexible wing structures [49], camber morphing wing [52]. $x^{2}$ Unmanned helicopters. $x^{3}$ Air brake. $x^{4}$ Control system. $x^{5}$ Power converter. $x^{6}$ Wing. $x^{7}$ Fault detection: fault-tolerant flight
design [54], fault-tolerant tracking control problem [55], tracking controller and fault detection and isolation system [61], and self-healing. Control (extended active fault-tolerant control) method [62]. 
Table 7. Evaluation of the papers categorized in the controls, identification, modeling category until 2015, according to the taxonomy referring to the paper content.

\begin{tabular}{|c|c|c|c|c|c|c|c|c|c|c|c|c|c|c|c|c|c|c|c|c|c|c|c|}
\hline \multirow{3}{*}{ Paper } & \multicolumn{4}{|c|}{ UAV Type } & \multicolumn{4}{|c|}{ Actuation Type } & \multicolumn{6}{|c|}{ Design Level } & \multicolumn{9}{|c|}{ Topics } \\
\hline & \multirow{2}{*}{ FxW } & \multirow{2}{*}{ FlW } & \multirow{2}{*}{ Mr } & \multirow{2}{*}{$\mathbf{O}$} & \multirow{2}{*}{$\mathbf{F}$} & \multirow{2}{*}{$\mathbf{E}$} & \multirow{2}{*}{$\mathbf{H}$} & \multirow{2}{*}{$\mathbf{O}$} & \multirow{2}{*}{ Ve } & \multirow{2}{*}{ PrS } & \multicolumn{4}{|c|}{ PrC } & \multirow{2}{*}{$\mathbf{K}$} & \multirow{2}{*}{ D } & \multirow{2}{*}{ Me } & \multirow{2}{*}{ PS } & \multirow{2}{*}{ MP } & \multirow{2}{*}{ Op } & \multirow{2}{*}{$\mathbf{V a}$} & \multirow{2}{*}{ FM } & \multirow{2}{*}{$\mathrm{C}$} \\
\hline & & & & & & & & & & & Mo & P1 & B & $\mathbf{O}$ & & & & & & & & & \\
\hline Grannan 2015 [63] & & & & & $x$ & & & & & $x$ & & & & & & $x$ & $x$ & $x$ & & & $x$ & & \\
\hline Theilliol 2015 [64] & & & $x$ & & & $x$ & & & $x$ & & & & & & & & $x$ & & & & $x$ & & $\mathrm{x}$ \\
\hline Wasik 2015 [65] & & & & & & $x$ & & & & $x$ & & & & & & $x$ & $x$ & & $x$ & $x$ & & & \\
\hline Szafranski 2014 [4] & & & $x$ & & & $x$ & & & & $x$ & & & & & & $x$ & & & & & & & $\mathrm{x}$ \\
\hline Gao 2012 [67] & $x$ & & & & & $x$ & & & $x$ & & & & & & & & $x$ & & & & & $x$ & $\mathrm{x}$ \\
\hline Hung 2012 [68] & $x$ & & & & & & $x$ & & & & & & & & & $x$ & $x$ & $x$ & $x$ & & & & $\mathrm{x}$ \\
\hline Koster 2011 [69] & & & & $x^{1}$ & & & $x$ & & $x$ & & & & & & & $x$ & $x$ & $x$ & $x$ & & & & $x$ \\
\hline Yu 2007 [70] & $x$ & & & & & $x$ & & & & & & & & & $x$ & & & $x$ & $x$ & & $x$ & & $x$ \\
\hline Tang 2005 [71] & $x$ & & & & & & $x$ & & $x$ & & & & & & & $x$ & $x$ & $x$ & $x$ & & $x$ & $x$ & $\mathrm{x}$ \\
\hline
\end{tabular}


Table 8. Evaluation of the papers categorized in the detailed design category from 2018, according to the taxonomy referring to the paper content.

\begin{tabular}{|c|c|c|c|c|c|c|c|c|c|c|c|c|c|c|c|c|c|c|c|c|c|c|c|}
\hline \multirow{3}{*}{ Paper } & \multicolumn{4}{|c|}{ UAV Type } & \multicolumn{4}{|c|}{ Actuation Type } & \multicolumn{6}{|c|}{ Design Level } & \multicolumn{9}{|c|}{ Topics } \\
\hline & \multirow{2}{*}{ FxW } & \multirow{2}{*}{ FlW } & \multirow{2}{*}{ Mr } & \multirow{2}{*}{$\mathbf{O}$} & \multirow{2}{*}{$\mathbf{F}$} & \multirow{2}{*}{$\mathbf{E}$} & \multirow{2}{*}{$\mathbf{H}$} & \multirow{2}{*}{$\mathrm{O}$} & \multirow{2}{*}{ Ve } & \multirow{2}{*}{ PrS } & \multicolumn{4}{|c|}{ PrC } & \multirow{2}{*}{$\mathbf{K}$} & \multirow{2}{*}{ D } & \multirow{2}{*}{ Me } & \multirow{2}{*}{ PS } & \multirow{2}{*}{ MP } & \multirow{2}{*}{ Op } & \multirow{2}{*}{ Va } & \multirow{2}{*}{ FM } & \multirow{2}{*}{$\mathrm{C}$} \\
\hline & & & & & & & & & & & Mo & P1 & B & $\mathrm{O}$ & & & & & & & & & \\
\hline Chew 2021 [72] & & & $x$ & & & & & & & & & $x$ & & & & & $x$ & & & & & & \\
\hline Hossain 2021 [73] & & & & & & $x$ & & & & & $x$ & & & & & & $x$ & & & & & & \\
\hline Liben 2021 [74] & & & & & & $x$ & & & & & $x$ & & & & & & & $x$ & & & $x$ & $x$ & \\
\hline Zhao 2021 [75] & $x$ & & & & & $x$ & & & & $x$ & & & & & & & & $x$ & & & & & \\
\hline Liu 2020 [77] & & & & & & & & & & & & & & & & & & & & & & & $\mathrm{x}$ \\
\hline Marcolini 2020 [78] & $x$ & & & & & $x$ & & & & & $x$ & & & & & & & $x$ & & & & & \\
\hline Ren 2020 [79] & & & $x$ & & & $x$ & & & & & $x$ & & & & & & $x$ & & & & & & \\
\hline Anzai 2019 [80] & & & $x$ & & & & & & & $x$ & & & & & & & $x$ & & & & & & \\
\hline Dai 2019a [81] & $x$ & & & & & $x$ & & & & $x$ & $x$ & & & & & & & & & & & $x$ & $x$ \\
\hline Guan 2019 [82] & & & & & & $x$ & & & & $x$ & $x$ & & & & & & & & & & & $x$ & $\mathrm{x}$ \\
\hline Guiatni 2019 [83] & & & $x$ & & & $x$ & & & & $x$ & $x$ & & & & & & & & & & & $x$ & $\mathrm{x}$ \\
\hline Liben 2019 [84] & & & & & & $x$ & & & & & $x$ & $x$ & & & & $x$ & $x$ & & & & & & \\
\hline De Simone 2018 [87] & & & $x$ & & & $x$ & & & & & & $x$ & & & $x$ & $x$ & & & & & & & $\mathrm{x}$ \\
\hline Kang 2018 [88] & $x$ & & & & $x$ & & & & & $x$ & & & & & & $x$ & $x$ & & $x$ & & $x$ & & \\
\hline Liu 2018 [89] & $x$ & & & & $x$ & & & & & $x$ & & & & & & & & & & & & & $x$ \\
\hline Mallavalli 2018 [90] & & & $x$ & & & $x$ & & & & & & & & & & & & & & & & $x$ & $\mathrm{x}$ \\
\hline Xu 2018 [91] & $x$ & & & & & $x$ & & & & $x$ & $x$ & & & & & & & $x$ & & $x$ & & & \\
\hline
\end{tabular}


Table 9. Evaluation of the papers categorized in the detailed design category from 2016 to 2017, according to the taxonomy referring to the paper content.

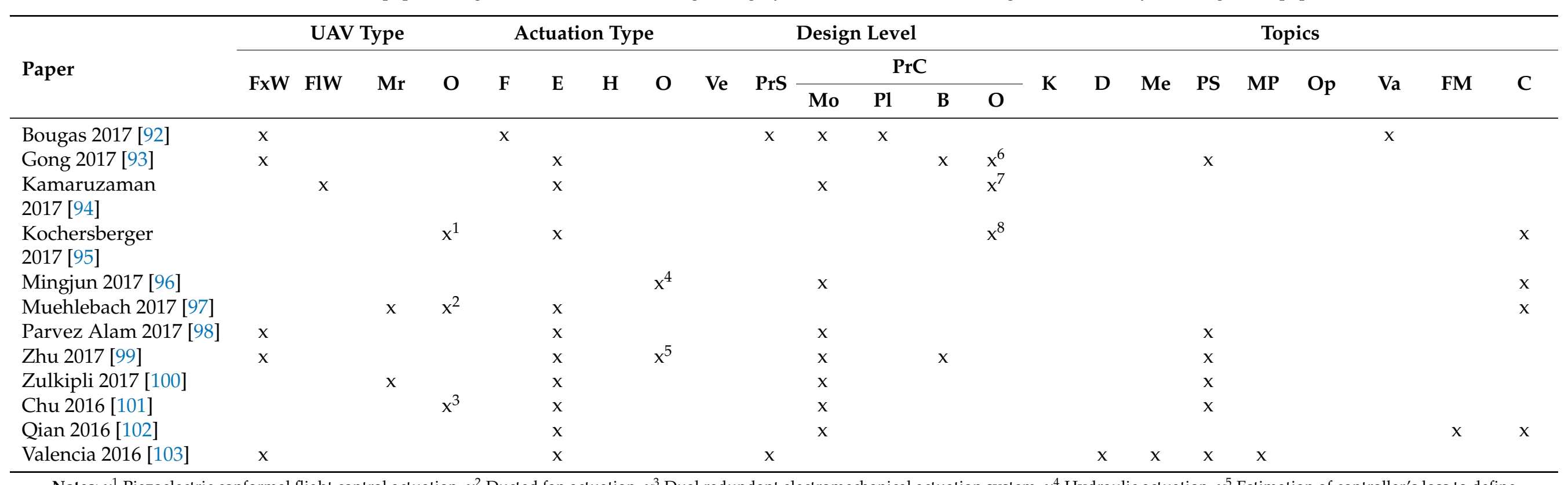

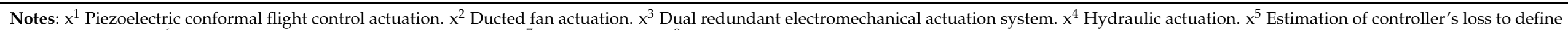
cooler system size. $x^{6}$ Fuel cell/battery hybrid UAV power system. $x^{7}$ Flapping wings. $x^{8}$ Morphing control surface. 
Table 10. Evaluation of the papers categorized in the detailed design category from 2011 to 2015, according to the taxonomy referring to the paper content.

\begin{tabular}{|c|c|c|c|c|c|c|c|c|c|c|c|c|c|c|c|c|c|c|c|c|c|c|c|}
\hline \multirow{3}{*}{ Paper } & \multicolumn{4}{|c|}{ UAV Type } & \multicolumn{4}{|c|}{ Actuation Type } & \multicolumn{6}{|c|}{ Design Level } & \multicolumn{9}{|c|}{ Topics } \\
\hline & \multirow{2}{*}{ FxW } & \multirow{2}{*}{ FlW } & \multirow{2}{*}{ Mr } & \multirow{2}{*}{$\mathbf{O}$} & \multirow{2}{*}{$\mathbf{F}$} & \multirow{2}{*}{$\mathbf{E}$} & \multirow{2}{*}{$\mathbf{H}$} & \multirow{2}{*}{$\mathbf{O}$} & \multirow{2}{*}{ Ve } & \multirow{2}{*}{ PrS } & \multicolumn{4}{|c|}{$\operatorname{PrC}$} & \multirow{2}{*}{$\mathbf{K}$} & \multirow{2}{*}{$\mathbf{D}$} & \multirow{2}{*}{ Me } & \multirow{2}{*}{ PS } & \multirow{2}{*}{ MP } & \multirow{2}{*}{ Op } & \multirow{2}{*}{ Va } & \multirow{2}{*}{ FM } & \multirow{2}{*}{$\mathrm{C}$} \\
\hline & & & & & & & & & & & Mo & P1 & B & $\mathbf{O}$ & & & & & & & & & \\
\hline Bryner 2015 [104] & & & & & $x$ & $x$ & & & & $x$ & & & & & & & & & & & & & \\
\hline $\begin{array}{l}\text { Chamseddine } \\
2015 \text { [105] }\end{array}$ & & & $\mathrm{x}$ & & & $\mathrm{x}$ & & & & & $x$ & & & & & & & & & & & $\mathrm{x}$ & $\mathrm{x}$ \\
\hline Khamlia 2015 [106] & & & $\mathrm{x}$ & & & $x$ & & & & $\mathrm{x}$ & & & & & & & & & & & & & $\mathrm{x}$ \\
\hline Bahoura 2014 [107] & & & & & & $x$ & & & & & $\mathrm{x}$ & & & & & & $x$ & & & $\mathrm{x}$ & & & \\
\hline Chamseddine & & & $\mathrm{x}$ & & & $\mathrm{x}$ & & & & $\mathrm{x}$ & & & & & & & & & & $\mathrm{x}$ & $\mathrm{x}$ & & \\
\hline 2014 [108] & & & & & & & & & & & & & & & & & & & & & & & \\
\hline Jackson 2014 [109] & $x$ & & & & & & & $x^{1}$ & & $\mathrm{x}$ & & & & & & $\mathrm{x}$ & & & & $x$ & & & \\
\hline Marimuthu 2014 [110] & & $x$ & & & & $x$ & & $x^{2}$ & & & & & & $x^{4}$ & & & $x$ & & & & & & \\
\hline Prazenica 2014 [111] & $\mathrm{x}$ & & & & & & & $x^{3}$ & & & $x$ & & & & & & & $x$ & & & & & $\mathrm{x}$ \\
\hline Bogusz 2011 [112] & $x$ & & & & & $x$ & & & & & $x$ & & & & & & & $x$ & & & & & \\
\hline Dönmez 2011a [113] & & $\mathrm{x}$ & & & & & & $x^{2}$ & & & & & & & & & & $x$ & & & & & $\mathrm{x}$ \\
\hline Lieh 2011 [115] & $x$ & & & & & $x$ & & & & $\mathrm{x}$ & & & & & & & $x$ & & & & $x$ & & \\
\hline Yu 2011 [116] & $x$ & & & & & $x$ & & & & & $x$ & & & & & & & & & & & & $x$ \\
\hline
\end{tabular}


Table 11. Evaluation of the papers categorized in the detailed design category until 2010, according to the taxonomy referring to the paper content.

\begin{tabular}{|c|c|c|c|c|c|c|c|c|c|c|c|c|c|c|c|c|c|c|c|c|c|c|c|}
\hline \multirow{3}{*}{ Paper } & \multicolumn{4}{|c|}{ UAV Type } & \multicolumn{4}{|c|}{ Actuation Type } & \multicolumn{6}{|c|}{ Design Level } & \multicolumn{9}{|c|}{ Topics } \\
\hline & \multirow{2}{*}{ FxW } & \multirow{2}{*}{ FlW } & \multirow{2}{*}{ Mr } & \multirow{2}{*}{$\mathbf{O}$} & \multirow{2}{*}{$\mathbf{F}$} & \multirow{2}{*}{$\mathrm{E}$} & \multirow{2}{*}{$\mathbf{H}$} & \multirow{2}{*}{$\mathbf{O}$} & \multirow{2}{*}{ Ve } & \multirow{2}{*}{$\operatorname{PrS}$} & \multicolumn{4}{|c|}{ PrC } & \multirow{2}{*}{$\mathbf{K}$} & \multirow{2}{*}{ D } & \multirow{2}{*}{ Me } & \multirow{2}{*}{ PS } & \multirow{2}{*}{ MP } & \multirow{2}{*}{ Op } & \multirow{2}{*}{ Va } & \multirow{2}{*}{ FM } & \multirow{2}{*}{ C } \\
\hline & & & & & & & & & & & Mo & $\mathbf{P l}$ & B & O & & & & & & & & & \\
\hline Sofla 2010 [117] & & & & $\mathrm{x}^{1}$ & & $x$ & & & & & & & & & & & $x$ & & & & & & \\
\hline Barrett 2006 [118] & $x$ & & & & & $x$ & & $x^{3}$ & & & $x$ & & & & & & & & & & & & $x$ \\
\hline Engeda 2006 [119] & & & & & & & & & & $x$ & & & & $x^{6}$ & & $x$ & & & & & & & \\
\hline Yoon 2006 [120] & $x$ & & & & & $x$ & & $x^{3}$ & & & & & & $x^{7}$ & & & & & & & & & $x$ \\
\hline Manzo 2005 [122] & & & & $x^{2}$ & & & & $x^{4}$ & & & $x$ & & & & & & $x$ & & & & & & \\
\hline Rajashekar 2005 [123] & & & & & & $x$ & & & & & $x$ & & & & & & $x$ & & & & $x$ & & \\
\hline Collie 2003 [124] & $x$ & & & & $x$ & & & & & $x$ & & & & & & & & $x$ & & & & & \\
\hline Ehrlich 2003 [125] & $x$ & & & & $x$ & & & & & $x$ & & & & & & & & $x$ & & & & & \\
\hline Lim 2003 [126] & $x$ & & & & & $x$ & & $x^{5}$ & & & $x$ & & & & & & $x$ & & & & & & \\
\hline
\end{tabular}

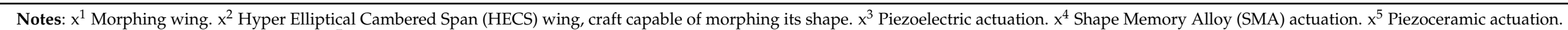
$x^{6}$ Design method for ducted fan system. $x^{7}$ Elevator control surface actuated by Lightweight Piezoceramic Composite Actuator (LIPCA). 
Table 12. Synthesis of the literature review, according to the taxonomy referring to the paper content. From the left, the analyzed parameters and the evaluated categories. For each category, the absolute number of papers assessing the characteristics and percentage are reported in the left and right column, respectively.

\begin{tabular}{|c|c|c|c|c|c|c|c|c|c|c|}
\hline \multicolumn{2}{|c|}{ Parameter } & \multicolumn{2}{|c|}{$\begin{array}{l}\text { Functional } \\
\text { Design, } \\
\text { Sizing }\end{array}$} & \multicolumn{2}{|c|}{$\begin{array}{c}\text { Optimization } \\
\text { Methods }\end{array}$} & \multicolumn{2}{|c|}{$\begin{array}{c}\text { Control, } \\
\text { Identification, } \\
\text { Modeling }\end{array}$} & \multicolumn{2}{|c|}{$\begin{array}{l}\text { Detailed } \\
\text { Design }\end{array}$} & \multirow{2}{*}{$\begin{array}{r}\text { Total } \\
49\end{array}$} \\
\hline \multirow{4}{*}{ 疍芯 } & FxW & 12 & $24.5 \%$ & 2 & $4.1 \%$ & 12 & $24.5 \%$ & 23 & $46.9 \%$ & \\
\hline & FlW & 0 & $0.0 \%$ & 0 & $0.0 \%$ & 1 & $20.0 \%$ & 4 & $80.0 \%$ & 5 \\
\hline & $\mathrm{Mr}$ & 5 & $15.4 \%$ & 0 & $0.0 \%$ & 14 & $43.8 \%$ & 13 & $40.6 \%$ & 32 \\
\hline & $\mathrm{O}$ & 1 & $5.9 \%$ & 2 & $11.8 \%$ & 9 & $52.9 \%$ & 5 & $29.4 \%$ & 17 \\
\hline \multirow{4}{*}{ 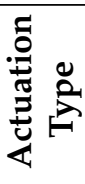 } & F & 0 & $0.0 \%$ & 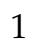 & $9.1 \%$ & 4 & $36.4 \%$ & 6 & $54.5 \%$ & 11 \\
\hline & E & 9 & $10.8 \%$ & 4 & $4.8 \%$ & 28 & $33.7 \%$ & 42 & $50.6 \%$ & 83 \\
\hline & $\mathbf{H}$ & 1 & $50.0 \%$ & 1 & $50.0 \%$ & 0 & $0.0 \%$ & 0 & $0.0 \%$ & 2 \\
\hline & O & 0 & $0.0 \%$ & 0 & $0.0 \%$ & 1 & $7.7 \%$ & 12 & $92.3 \%$ & 13 \\
\hline \multirow{6}{*}{ 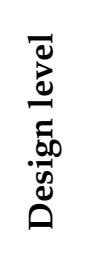 } & Ve & 4 & $30.8 \%$ & 1 & $7.7 \%$ & 8 & $61.5 \%$ & 0 & $0.0 \%$ & 13 \\
\hline & PrS & 11 & $23.4 \%$ & 2 & $4.3 \%$ & 15 & $31.9 \%$ & 19 & $40.4 \%$ & 47 \\
\hline & Mo & 0 & $0.0 \%$ & 2 & $5.9 \%$ & 5 & $14.7 \%$ & 27 & $79.4 \%$ & 34 \\
\hline & Pl & 0 & $0.0 \%$ & 1 & $12.5 \%$ & 1 & $12.5 \%$ & 6 & $75.0 \%$ & 8 \\
\hline & B & 0 & $0.0 \%$ & 0 & $0.0 \%$ & 1 & $33.3 \%$ & 2 & $66.7 \%$ & 3 \\
\hline & $\mathrm{O}$ & 2 & $9.1 \%$ & 0 & $0.0 \%$ & 13 & $59.1 \%$ & 7 & $31.8 \%$ & 22 \\
\hline \multirow{9}{*}{$\frac{0}{\frac{0}{a}}$} & $\mathbf{K}$ & 0 & $0.0 \%$ & & $0.0 \%$ & 6 & $85.7 \%$ & 1 & $14.3 \%$ & 7 \\
\hline & D & 10 & $20.8 \%$ & 5 & $10.4 \%$ & 25 & $52.1 \%$ & 8 & $16.7 \%$ & 48 \\
\hline & Me & 15 & $25.4 \%$ & 4 & $6.8 \%$ & 23 & $39.0 \%$ & 17 & $28.8 \%$ & 59 \\
\hline & PS & 11 & $23.4 \%$ & 3 & $6.4 \%$ & 17 & $36.2 \%$ & 16 & $34.0 \%$ & 47 \\
\hline & MP & 4 & $17.4 \%$ & 2 & $8.7 \%$ & 15 & $65.2 \%$ & 2 & $8.7 \%$ & 23 \\
\hline & Op & 4 & $21.1 \%$ & 4 & $21.1 \%$ & 5 & $26.3 \%$ & 6 & $31.6 \%$ & 19 \\
\hline & Va & 14 & $25.9 \%$ & 4 & $7.4 \%$ & 30 & $55.6 \%$ & 6 & $11.1 \%$ & 54 \\
\hline & FM & 0 & $0.0 \%$ & 0 & $0.0 \%$ & 11 & $55.0 \%$ & 9 & $45.0 \%$ & 20 \\
\hline & C & 6 & $10.7 \%$ & 0 & $0.0 \%$ & 28 & $50.0 \%$ & 22 & $39.3 \%$ & 56 \\
\hline
\end{tabular}

\subsection{The Integrated Functional Design Framework}

According to data extracted from literature, the functional design of the propulsion system of UAVs should be grounded on an inclusive framework, which integrates different kinds of requirements. Figure 3 synthesizes the interpretation rationale of the context, which was adopted to outline the integrated functional design framework. The analysis of the mission profile, power supply, and actuation sub-systems allowed determining peculiar requirements for the design of the final device; nonetheless, constraints related to technical limits, as well as normative framework-related requirements can also be identified. For instance, the maximum UAV dimensions and cruise velocity could be considered technical requirements, whereas given the drone's size, the operating altitude is a normative framework-dependent constraint. Further constraints could also be added when considering additional factors potentially affecting the design or the selection criteria for some components, such as the personal preferences of the designer and/or manufacturer (e.g., sustainability in processes or production technologies), as well as management-related attributes (e.g., kind of vendor service contracts, provider reliability, and quality of the supporting channel, or consistency with current infrastructures) [127]; Figure 3 collects them in the custom requirements set. 


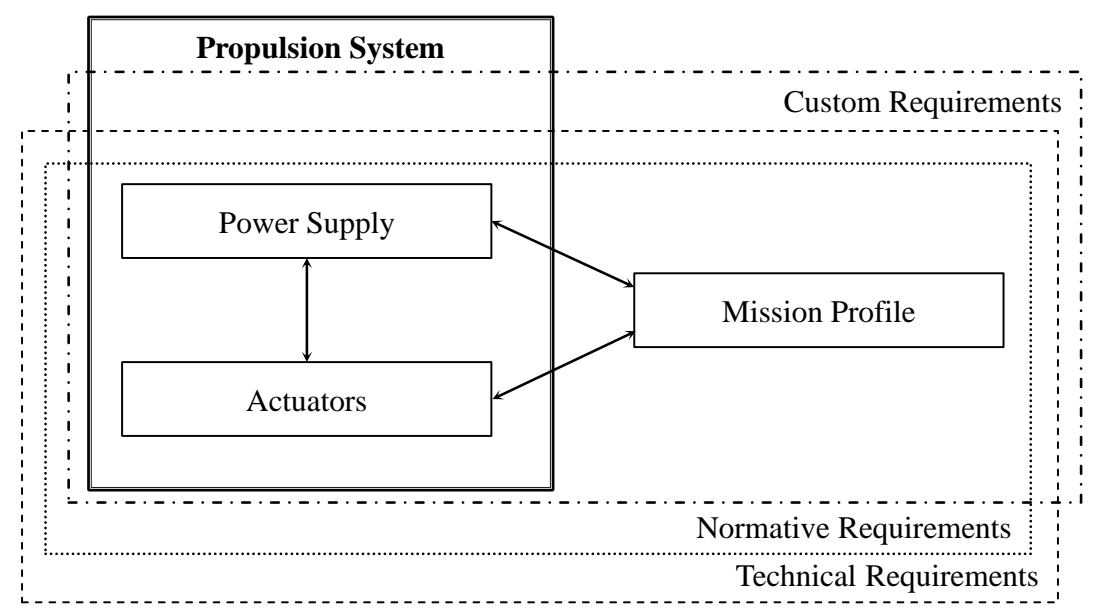

Figure 3. Schematic of the integrated functional design framework: the propulsion system is modeled as the set of the power supply and actuator sub-systems, interacting each other and with the mission profile module. All the blocks are affected by constraints imposed by technical, normative frameworkrelated, or custom requirements.

Figure 4 depicts at a glance the integrated functional design framework for the identification of the propulsion system. More than comparing commercial off-the-shelf products to select the most suitable element, this procedure was meant to support the early stages of the design process, as it aimed to identify the functional characteristics that the further detailed design should include for the selection of the final components.

The procedure was composed of three main stages: (i) the identification of the requirements for the overall UAV, (ii) the selection of the actuation subsystem, and (iii) the sizing of the power supply subsystem. Within the first stage, the synthesis of the initial design constraints was driven by technical requirements, such as desired payload, cruise velocity, and round-trip, by normative-related constraints, such as a total mass at take-off higher or lower than the limit of $25 \mathrm{~kg}$ stated in the Italian regulations for drones, and by custom requirements, such as the preference for a hybrid or electric propulsion system, composed of an odd or even number of direct-drive outrunner multi-rotor units, evenly distributed on the fuselage or specifically located. These constraints define a first attempt at the actuation category, from which a set of possible actuator candidates can be identified.

Within the second stage, the main design constraints related to working conditions and tasks were outlined. Once having selected the desired actuator type (e.g., AC or DC, brushed or brushless), the analysis of the mission profile allowed defining the main kinematic constraints required for the UAV. For a first sizing of the actuation components, the worst working condition should be considered. Besides, starting from a free-body analysis of the UAV, the generalized forces (meant as linear forces and torques) acting on the device were depicted, and the characteristics equations of the system were extracted. Expected generated thrust forces $T_{a d v}$ and $F_{\text {Climb }}$ for advancement and climb respectively were identified for each possible actuator unit, whereas lift and drag coefficients were evaluated with respect to the angle of attack $\alpha$ for each possible propeller, as well as voltage, current, and energy consumption $E_{C}$. If the values of $T_{R}(t)$ and $a_{R}(t)$ can be considered the main design constraints according to the expected mission profile, $T_{P}(t)$ and $a_{P}(t)$ can be then defined as the corresponding parameters for the propulsion system candidates, distinctive for the specific solution. Those values can be computed by solving the characteristic equilibrium equations of the UAV's free-body diagram. In order to be suitable, the actuation candidate must assure an acceleration $a_{P}(t)$ higher than the maximum value of the required acceleration $a_{R}$ for at least one configuration of the throttle percentage (or instant $t$ ). The best candidate for the actuation system reaches the required acceleration at lower throttle percentage values, the other characteristics being equal. Several methods can be adopted to evaluate the introduced quantities: for instance, at this design stage, the lift and drag coefficients can be estimated as approximate values through 
numerical computation (e.g., in the Xfoil 6.97 environment), or different kinematic and dynamic models can be adopted to analyze the vehicle aerodynamics (such as the particle model or a system of rigid bodies). Therefore, the same quantities can be defined according to different methodological hypotheses and described by distinct formal expressions.

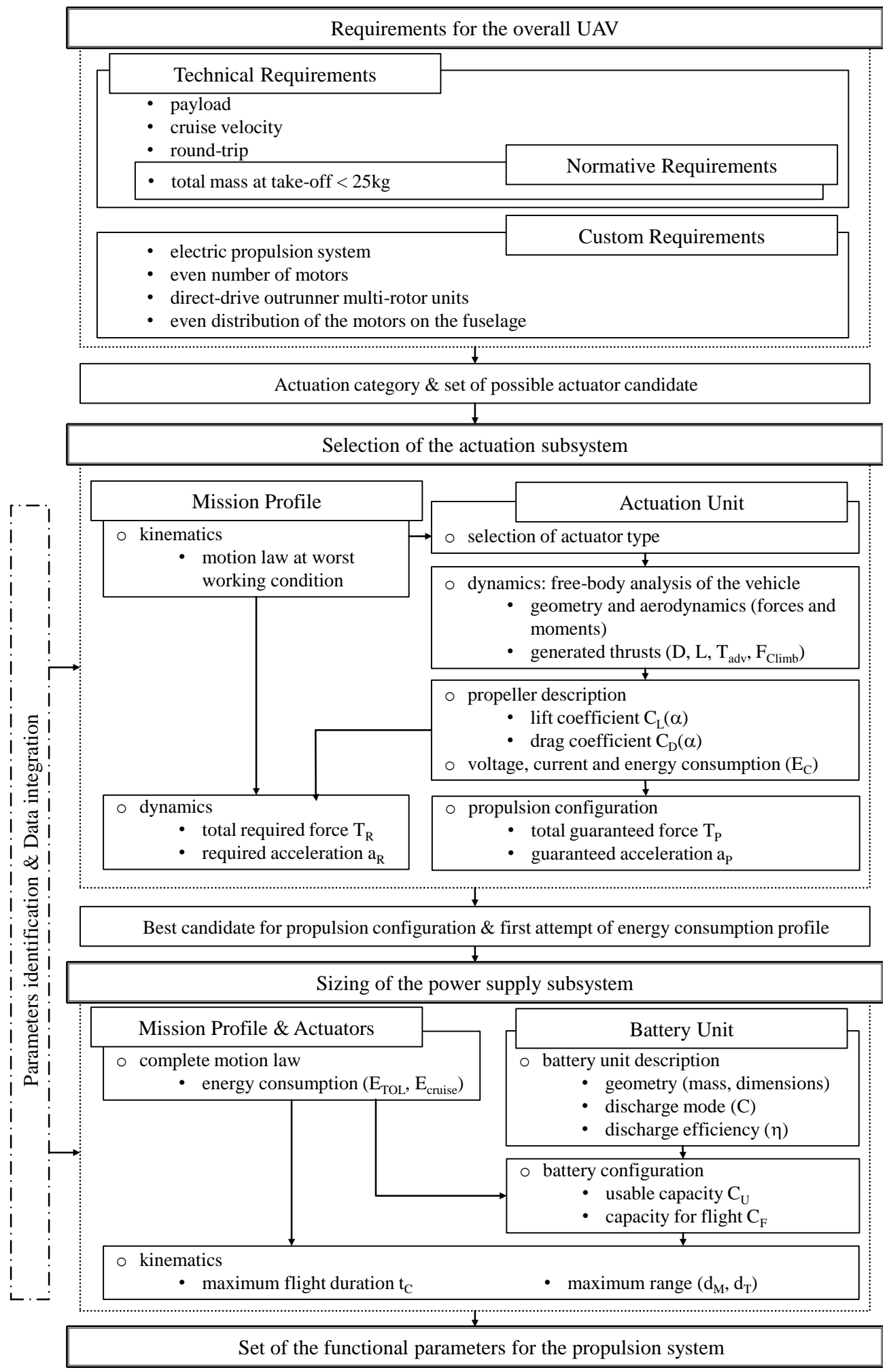

Figure 4. Synthetic road-map of the integrated functional design framework for the propulsion system identification. 
The third stage of the procedure allowed sizing the power supply subsystem. As custom requirements, the preference for an even number of Li-ion batteries could be considered, and a maximum value of the Depth of Discharge $(D o D)$ should be settled. Given the selected actuation, the energy consumption $E_{T O L}$ and $E_{c r u i s e}$, required for the take-off or landing and cruise phase of a mission, respectively, can be evaluated. Those values depend on the kind of mission, for instance: A monitoring mission would require a take-off phase, then loitering until at last the maximum allowed range $d_{M}$, and a final landing back at the base. On the contrary, in a delivery mission, the drone is expected to transfer a good from the starting point to a defined target and then return to the base, so the mission profile should foresee a take-off phase, the cruise until at least the maximum allowed distance $d_{T}$, the landing at the target position, then the return trip composed once again of the take-off, cruise, and landing phases. For delivery missions, even more trips could be conceived of within a single route: in this case, the energy consumption corresponding to an additional landing and take-off pair should be also considered for each additional target. Besides, the selection of a battery type allows identifying the discharge mode $C$ and efficiency $\eta$. The definition of the number of included batteries and the choice of the maximum acceptable level of $D o D$ for each battery enable computing the usable capacity $C_{U}$ of the power system. Once having settled the number of desired trips, the capacity of flight $C_{F}$ can be consequently evaluated as the remaining capacity, the net of the required $E_{T O L}$. The maximum flight duration $t_{C}$ can then be computed as the ratio of the remaining capacity for flight $C_{F}$ to the power consumption in the cruise phase. Finally, the maximum allowed distance $d_{M}$ or $d_{T}$, for monitoring or delivery missions, respectively, can be estimated in two ways: (i) with an average estimation, as the product between the maximum flight duration $t_{C}$ and the desired cruise velocity set by the mission requirements, and (ii) with a punctual evaluation of the mission profile, as the maximum distance traveled by the drone when the battery reaches the minimum acceptable value of the State of Charge (SoC), complementary to $100 \%$ of the imposed DoD.

\section{Discussion}

\subsection{Literature Analysis}

Focusing on the distribution of the papers among the proposed thematic categories, the results suggested a higher interest of the scientific community in the design of specific elements of UAVs, as the high rate of studies in the detailed design category demonstrated. As Table 12 describes, the highest percentage values coincided with problems related to well-defined technical areas, such as innovative or unconventional components, especially actuators and propellers.

Furthermore, the control, identification, modeling category presented a high number of papers: works collected within this class mainly focused on optimized and robust control techniques, as well as mission-planning procedures.

Fewer papers were devoted to optimization methods instead. From a general perspective, traditional methods for the propulsion system definition were mostly based on design experience or trial-and-error strategies [38]. These techniques often are grounded on identification procedures for the main subset components; aiming at comparing potential candidates and dynamically selecting the best solution according to the evolution of the design process, large and constantly updated datasets are necessary in order for those selection processes to be effective. In 2019, Dai et al. proposed to simplify and decouple the whole optimization design problem into several analytically solved sub-problems [38]. In 2021, Zhang at al. depicted on the contrary an overall optimization, described as a multidisciplinary approach, since it concurrently evaluates analysis models peculiar to multiple disciplines within a common optimization framework [27]. Comparing these last methods, the decoupling approach drastically reduces the computational burden for the implementation of the optimization procedure, whereas the multidisciplinary strategy assures the optimum matching of the propulsion system components. Nonetheless, in order to identify the best solution, this kind of approach unflinchingly evaluates at the 
same time a potentially huge amount of candidates; therefore, the optimization process should be likely repeated in case new candidates would emerge. Moreover, these kinds of methods are based on cost functions, which only allow considering quantitative technical constraints for the definition of the requirements for the components' selection. As a consequence, these approaches could be hardly adopted in the very early stages of the design process, since they expect for the main strategic aspects of the design concept, such as type of actuation system or drone size, to have been already settled. Besides, additional constraints can also be considered, such as: a specific application, the normative framework, or designer preferences.

Finally, nineteen products were classified within the functional design, sizing category. According to the literature, in the choice and subsequent sizing of the propulsion system, some parameters can be considered fundamental: efficiency, reliability, size, mass, power, energy density, complexity, and cost-effectiveness. For UAVs presenting a size consistent with our case study, two possible technologies can provide power generation: electric motors (with energy stored in batteries and, possibly, together with supercapacitors) and thermal engines (with gasoline, methane, or hydrogen fossil fuel). The energy density of fossil fuels is higher than that of batteries, but engines available for UAV applications have low efficiency, a high thermal and acoustic signature, and complex control, and these can cause stability problems. Electric motors have features that make them the most suitable choice for smaller UAVs, such as high efficiency, reliability, low noise, a low thermal signature, advanced control devices and high maneuverability. Moreover, they have the advantage of being more environmentally friendly devices as they do not emit pollutants. In some cases, electric and thermal motors are both used on the same UAV to combine the advantages of the two technologies. In any case, the solution must be identified in terms of the choice of propulsion technology that better suits (e.g., by efficiency, costs, or dimensions) the application in question, considering the specific data of the UAV to be designed and the peculiarities of each technology. Considering the use of electric motors, two electric motors are used currently in drones: brushed and brushless DC motors. For smaller UAVs, the choice falls most commonly to Brushless DC motors (BLDC) then brushed DC motors, because of the high power density, efficiency, reliability, speed, ease of control, low maintenance costs, and long lifetime [128]. Nevertheless, brushed motors can be also used to propel micro aircraft, and brushless motors are used for low-power UAVs (some watts) as well as for high-power UAVs (tens of kilowatts). The speed control of a BLDC motor is then usually managed by the Electronic Speed Control (ESC), based on an electronic circuit that regulates the speed. The choice of the energy source represents another fundamental aspect of the functional design of the propulsion system. Possible solutions are batteries (among which there are different types such as Li-ion, alkaline, LiPo, $\mathrm{NiCd}$, etc.), capacitors, supercapacitors, electrolytic capacitors, solar cells, and fuel cells, which can be used alone, but also combined in a configuration called hybridization [27,129]. These different solutions have different potentials in terms of specific power and specific energy, as well analyzed by Boukoberine et al. [128], and hybridization allows combining advantages and performances and balancing their limitations. When different energy sources are used in a UAV, the real-time power splitting among the available sources must be managed by a Power Management System (PMS), which can be implemented with an active or a passive strategy [130]. The choices to be made in the functional design phase for the energy aspect therefore also concern the aspects of the solution to be adopted for energy management, depending on the chosen energy sources and storage systems [131,132].

The analysis of the scientific literature emphasized a remarkable variability in works' number and main topics with respect to the drone size, although few research works focused in particular on medium-sized UAVs, e.g., with a mass at take-off close to $25 \mathrm{~kg}$, which in the Italian regulation represents a crucial threshold strongly affecting the design process. Nonetheless, the high number of works concerning the sizing and optimization of the propulsion system reflects the importance of this element within the design process. 
Regarding the contents of the papers, evaluated thanks to the set of parameters defined with the second taxonomy, the main results of the literature review are briefly reported in the following sections.

\subsubsection{UAV Types}

Considering the UAV type, the focus of most of the studies was divided between fixed-wing UAVs and multirotor vehicles. Within the latter sub-category, fourteen papers explicitly referred to quadrotor systems $[16,24,31,32,34,35,43,44,50,79,83,90,105,106]$, two to hexarotor UAVs [64,133], one to bicopters [85] and one to octocopter drones [108], respectively. Several papers did not specifically state a UAV type target in terms of architecture configuration, whereas others focused more properly on the drone characteristics, as the specific performance that the UAV needed to assure, or the kind of mission in which the system was expected to be engaged [36,40-42]. Apart from the fixed-wing and multirotor UAVs, five papers described flapping-wing drones [60,94,110,113,114], paying particular attention to the design of the flapping system itself.

The current taxonomy highlights the architectural configurations of UAVs, therefore allowing capturing possible differences among design approaches, which emphasize the characteristics of the drones connected to geometric- and dynamic-related factors. An alternative taxonomy could investigate the UAV size, for instance to compare the number of papers devoted to each size, as an indicator of the academic interest in the topic, market shares of the products in the corresponding categories, as an indicator of the impact of research, or the number of filed patents referring to the different UAV size, as an indicator of the business interest.

\subsubsection{Actuation Types}

The type of actuation chosen to generate motion in UAVs is highly influenced by many factors such as the power and energy densities required by the application and allowed by the solution, mission requirements, and drone size, shape, flight mode, mission, or endurance [2]. Three main solutions for actuators were adopted: fuel engines, electric motors, and hybrid solutions. Fuel engines include mainly gas turbine engines, jet engines, gas engines, and internal combustion engines; electric motors more commonly used in UAVs are brushless and brushed DC motors; the hybrid solution is based on a fuel engine (an internal combustion engine [33], a gas turbine [53], or a turbojet engine [40]) used as the primary source of energy, while the actuation is based on an electric motor. The main advantages of fuel engine-based solutions are high power and energy densities, long flight autonomy, and large payload range, making them the primary choice for larger drones. The gas turbine engine exhibits the highest performances among fuel engines, in terms of power-to-weight ratio, reliability, and operation time. Fuel engines' performances become worse for small-scale UAV applications due to a lower fuel economy, lower efficiency, and high noise level. Moreover, their acoustic emissions and thermal signature are high, and the theme of environmental sustainability (due to the shortage of fossil fuels, global warming, and increasing pollution) is a factor to their detriment and pushes toward the adoption of electric propulsion [129]. The choice of electric motors in small-to-medium-sized UAVs is the most common $[9,64,100,106]$, due to their multiple advantages: high efficiency, low noise emission, low thermal dissipation, reliability, no pollutant emission, self-starting, controllability, and high maneuverability. The brushless DC motors' increasing diffusion among electrically actuated UAVs was confirmed by the literature review: indeed, for the totality of the analyzed articles with electric propulsion UAV, the motor used was a brushless DC. The significant weight of the power storage system (commonly a battery) is the main disadvantage of purely electric-powered UAVs. The hybrid solution benefits from the advantages of both fuel engines and electric solutions, overcoming some of their most important disadvantages. A hybrid UAV may allow long flights, with a reduced heat signature and acoustic emissions, lower battery weight due to the battery recharging during flight, reduced fuel consumption, and functioning 
in an electric-alone mode when necessary with reduced noise. In a limited number of cases $[7,11]$, UAVs have an electric actuation solution where solar energy, as the primary energy, is used to recharge the battery. Other studies [25,93] considered fuel-cell/battery hybrid UAV power systems. In [93], a performance comparison was made between the use of a metal hydride hydrogen storage system and a compressed hydrogen system. Finally, actuators based on shape memory alloys, piezoelectric or piezo-ceramic actuators, MEMS, or strain actuation $[46,94,95,110,113,114,117,118,120-122,126]$ are used to modify the geometry of some elements of the drone (such as the wings), with the aim to allow some motion adjustments.

\subsubsection{Design Level}

For the classification of the papers based on the design level, few works were included in the class vehicle (12 among 123): 46 were focused on the Propulsion System (PrS) and 69 on a specific propulsion component. The papers of this last class were further subdivided into sub-classes, by considering the motor (35), the propeller (8), the battery (3), or another component (23). The papers in the class vehicle were related to the design of the whole vehicle at different levels, for example: $\mathrm{Li}$ in [7] presented a general optimal design method for solar-powered UAVs; Stepaniak in [24] described the design of a quadrotor UAV, which was used as a navigation sensor testbed; Nigro in [44] presented a preliminary study on a new concept of a fully actuated UAV, which can simultaneously modify the tilting angle of all the propellers; Koster in [69] presented a three-meter scale model aircraft, named Hyperion, developed by student engineering teams whose design concept included a novel hybrid gas/biodiesel-electric power train as a green aircraft technology. In the works that dealt with the propulsion system as a whole, very different themes were treated, and some examples are summarized below. Dantsker et al. [11] provided an overview of a propulsion system optimization tool and system power model applied to a long-endurance solar-powered UAV; Castaneda et al. [16] addressed practical guidelines for propulsion system design and implementation in a quadrotor micro air vehicle; Lu et al. [53] presented the design of a gasoline-electric hybrid propulsion system implemented in a micro triple tilt-rotor VTOL; Hiserote et al. [22] discussed the conceptual design of a high-endurance UAV and the preliminary design and experimental tests on a hybrid propulsion system; Guo et al. [15] presented an impulsive thruster propulsion system that could be used in a multi-modal UAV capable of sustained aerial flight, locomotion in water, and deployment from a tube filled with compressed air; Bondyra et al. [57] presented the experimental verification of the performance of a X8 quadcopter, which extended the original quadrotor concept to eight motors, arranged in four coaxial pairs; Kang et al. [88] described a turbo-compression system design and a performance analysis procedure for a highaltitude long-endurance UAV; Lieh et al. [115] compared four hybrid propulsion models; Collie et al. [124] described the propulsion system and integration design of a subscale turbojet UAV. With reference to this specific theme, it emerged that for the functional project of the propulsion system in the literature, there were some works focused on specific types of UAVs, but a procedural synthesis was not present for medium-sized electric-propelled multirotor UAVs. The papers in the sub-class propulsion were mainly focused on the motor, and almost all were related to the design or characterization of brushless DC motors, as in the following cases. Lee et al. [42] put forward the optimal design method for UAVs and interior permanent magnet motors for drones that require high thrust of high rotational speed; Marcolini et al. [78] investigated the design of a multiphase coreless axial flux permanent magnet machine with concentrated windings, to obtain very high power and torque densities; Liben et al. [84] presented an analytical design method to develop a ring motor that was wrapped around the outer diameter of a propeller; $\mathrm{Xu}$ et al. [91] presented a novel parameter design method for a DC brushless motor; Parvez Alam et al. [98] aimed at the design and development of a small-scale test rig setup for the measurement of the thrust of any brushless DC motor; Zulkipli et al. [100] studied the characteristics of a brushless direct current motor for the purpose of multicopter design. A very limited number of works 
dealt with actuators based on other technologies, such as the work of Mingjun et al. [96], who presented a new type of compact smart hydraulic actuator, or of Jims John Wessley [40], who presented the design of major components of a turbojet engine that could produce thrust suitable for medium-altitude UAVs. Few papers fell into the sub-classes propeller and batteries, for example: the work of Van Treuren et al. [35], in which three different five-bladed propellers were tested and compared, or of Oukassi et al. [45], who presented the manufacturing and characterization results of biomimetic-shaped thin-film batteries. In the sub-class others, some specific components were investigated: in three of them [31,34,39], it was the flight controller; in the paper of Hossain et al. [12], it was a linear servo-actuator variable-span morphing wing; in the work of He et al. [51], it was the power converter; in the study of Kochersberger et al. [95], it was a morphing control surface; in two papers $[120,121]$, it was the elevator control surface actuated by Lightweight Piezoceramic Composite Actuator (LIPCA).

\subsubsection{Integration Level}

The number of topics assigned to each paper was evaluated as an indicator of the integration level of the work, since it conveyed the involvement of more areas of interest of the considered design procedure. According to the results, over $28 \%$ of the papers were associated with a single topic. Among them, the areas presenting the higher rates were mechanics, power supply, and control. Papers presenting three or fewer topics represented almost $70 \%$, whereas papers with six or more topics covered $5 \%$ of the total. Analyzing the topics independently, as Table 12 depicts, mechanics ( 59 papers, $17.7 \%$ ), control (56 papers, $16.8 \%$ ), and validation (54 papers, $16.2 \%$ ) were the topics with higher rates. Dynamics and power supply still presented close values (48 papers, $14.4 \%$, and 47 papers, $14.1 \%$ respectively), whereas the set of remaining topics, evaluated as a whole, covered $20.7 \%$.

Data also suggested a correlation of integration and design levels: indeed, the papers presenting the highest numbers of associated topics were devoted to vehicle or propulsion system design levels, whereas the works with the lowest rates mainly focused on the design of specific propulsion components. This consideration further supported the hypothesis that an optimal design framework for complex systems such as UAVs should be grounded on an integrated rationale, as the first stages of the functional design process.

\subsection{The Integrated Design Framework}

Beside the several methods for UAVs design [8-10,25,134], optimization techniques for the iterative identification of the best propulsion system were also present $[16,27,29,124]$. Those methods apply well once the design exceeds the concept phase and the key elements of the system have been established, given that they typically allow evaluating detailed aspects from different fields, to identify components with as much accuracy as possible (ideally, to the off-the-shelf level). Nevertheless, an almost complete freedom to operate could also represent a significant drawback in the very early stages of the process, especially for complex systems such as UAVs, since the identification of the detailed characteristics in the overall system and components demands an already settled definition of the main strategic aspects of the drone architecture.

A suitable design methodology should therefore enable an integrated analysis, which includes fluidics and fight dynamics evaluations to motion profile and kinematics data. In this perspective, the procedure described in Figure 4 represents a functional framework, since it allows performing a selection of preliminary candidates, suitable for further optimization processes, by evaluating the constraints and expected characteristics of the components. One of the main advantages of the proposed framework is its inherent flexibility: since it represents a guideline for the model definition, non-quantifiable constraints can be assessed as well, such as the preference for a hybrid or an electric propulsion system. However, to enable the sizing of the power supply system, a proper characterization of the components in the propulsion unit is needed, and an integration or validation of the 
data provided by the manufacturer for the selected pair of actuator and propellers could be necessary, especially in components suitable for medium-sized UAVs.

\section{Conclusions}

The design of the propulsion system for UAVs presents almost unique characteristics, demanding an inclusive multidisciplinary approach from the first design stages. A review of the scientific literature was performed with a systematic approach, and the selected papers were evaluated according to a dual custom classification taxonomy, which investigated the primary aim and specific content of the works. Design methods dramatically change depending on the possible application cases and expected working conditions. According to this, the results of the literature review stated a high interest of the scientific community towards the design of specific elements of UAVs. Finally, a framework for the preliminary study of the propulsion system in UAVs was outlined and proposed, according to an integrated functional design approach.

Author Contributions: Conceptualization, C.A., F.C., M.P., M.S., M.T., and S.Z.; methodology, C.A., M.P., and M.T.; software, F.C. and M.S.; validation, C.A., F.C., and M.S.; formal analysis, M.P. and M.T.; writing — original draft preparation, C.A. and M.T.; writing—review and editing, F.C., M.P., M.S., and S.Z.; project administration, C.A.; funding acquisition, M.S. and S.Z. All authors read and agreed to the published version of the manuscript.

Funding: This research was partially funded by Regione Lombardia, Call Hub Ricerca e Innovazione, within the project "MoSoRe@Unibs-Infrastrutture e servizi per la Mobilità Sostenibile e Resiliente", 2020-2022.

Conflicts of Interest: The authors declare no conflict of interest.

\section{References}

1. Schroth, L.; Bödecker, H.; Radovic, M. Drone Market Report 2020-2025. Technical Report. June 2020. Available online: https:/ / droneii.com/ (accessed on 1 June 2020).

2. Hassanalian, M.; Abdelkefi, A. Classifications, applications, and design challenges of drones: A review. Prog. Aerosp. Sci. 2017, 91, 99-131. [CrossRef]

3. Kahn, J.M.; Katz, R.H.; Fellow, A.; Pister, K.S.J. Next Century Challenges: Mobile Networking for "Smart Dust". In Proceedings of the 5th Annual ACM/IEEE international Conference on Mobile Computing and Networking, Seattle, WA, USA, 15-19 August 1999; pp. 271-278.

4. Szafranski, G.; Czyba, R.; Blachuta, M. Modeling and identification of electric propulsion system for multirotor unmanned aerial vehicle design. IEEE Comput. Soc. 2014, 470-476. [CrossRef]

5. Aksugur, M.; Inalhan, G. Design methodology of a hybrid propulsion driven electric powered miniature tailsitter unmanned aerial vehicle. J. Intell. Robot. Syst. Theory Appl. 2010, 57, 505-529. [CrossRef]

6. Uninhabited Air Vehicles: Enabling Science for Military Systems; National Academies Press: Washington, DC, USA, 2000. [CrossRef]

7. Li, X.; Sun, K.; Li, F. General optimal design of solar-powered unmanned aerial vehicle for priority considering propulsion system. Chin. J. Aeronaut. 2020, 33, 2176-2188. [CrossRef]

8. Aksugur, M.; Inalhan, G.; Beard, R. Hybrid propulsion system design of a VTOL tailsitter UAV. SAE Tech. Pap. 2008. [CrossRef]

9. Bershadsky, D.; Haviland, S.; Johnson, E. Electric Multirotor Propulsion System Sizing for Performance Prediction and Design Optimization; American Institute of Aeronautics and Astronautics Inc.: Reston, VA, USA, 2015.

10. Zhao, X.; Zhou, Z.; Zhu, X. Design of a Lift-Propulsion VTOL UAV System; Institute of Electrical and Electronics Engineers Inc.: New York, NY, USA, 2018; pp. 1908-1913. [CrossRef]

11. Dantsker, O.; Caccamo, M.; Imtiaz, S. Propulsion System Design, Optimization, Simulation, and Testing for a Long-Endurance Solar-Powered Unmanned Aircraft; American Institute of Aeronautics and Astronautics Inc.: Reston, VA, USA, 2020; pp. 1-18. [CrossRef]

12. Hossain, A.; Wang, W.; Yue, H. Design and analysis of a linear servo-actuated variable-span morphing wing. INCAS Bull. 2020, 12, 71-82. [CrossRef]

13. Saemi, F.; Benedict, M.; Beals, N. Development of a brushless DC motor sizing algorithm for a small UAS design framework. In Proceedings of the Vertical Flight Society's 76th Annual Forum and Technology Display, Fairfax, VA, USA, 6-8 October 2020.

14. Siswoyo Jo, R.; Tan, A.; Tee Kit Tsun, M.; Siswoyo Jo, H. Design and modeling of actuation system of unmanned tricopter with thrust-vectoring front tilt rotors for sustainable flying. In Proceedings of the International Conference of Aerospace and Mechanical Engineering 2019; Springer: Singapore, 2020; pp. 45-55. [CrossRef]

15. Guo, D.; Bacciaglia, A.; Ceruti, A.; Marzocca, P.; Bil, C. Design and Development of a Transition Propulsion System for Bimodal Unmanned Vehicles; Institute of Electrical and Electronics Engineers Inc.: New York, NY, USA, 2018; pp. 549-558. [CrossRef] 
16. Castaneda, H.; Cantu, L.; Leal, A.; Gordillo, J. Guidelines for Propulsion System Design and Implementation in a Quadrotor MAV; Institute of Electrical and Electronics Engineers Inc.: New York, NY, USA, 2017; pp. 1302-1308. [CrossRef]

17. Kotarski, D.; Piljek, P.; Brezak, H.; Kasać, J. Design of a Fully Actuated Passively Tilted Multirotor UAV with Decoupling Control System; Institute of Electrical and Electronics Engineers Inc.: New York, NY, USA, 2017; pp. 385-390. [CrossRef]

18. Heim, M.; Pyne, K.; Bialy, A.; Burns, M.; Mohan, G.; Beaty, N.; MacNeal, C.; Weit, C.; Brady Doepke, E.; Kevorkian, C.; et al. Design and demonstration of a flexible matrix composite actuated flap in a UAV. Am. Soc. Mech. Eng. 2015, 2. [CrossRef]

19. Li, Y.; Liu, L.; Ma, X.; Tu, H. Design of Hybrid Electric Propulsion System for Long Endurance Small UAV; American Institute of Aeronautics and Astronautics Inc.: Reston, VA, USA, 2012. [CrossRef]

20. Lindahl, P.; Moog, E.; Shaw, S. Simulation, design, and validation of an UAV SOFC propulsion system. IEEE Trans. Aerosp. Electron. Syst. 2012, 48, 2582-2593. [CrossRef]

21. Capata, R.; Marino, L.; Sciubba, E. Preliminary design of a hybrid propulsion system for high-endurance UAV. ASME Int. Mech. Eng. Congr. Expo. 2010, 1, 107-112. [CrossRef]

22. Hiserote, R.; Harmon, F. Analysis of Hybrid-Electric Propulsion System Designs for Small Unmanned Aircraft Systems; American Institute of Aeronautics and Astronautics Inc.: Reston, VA, USA, 2010. [CrossRef]

23. Lindahl, P.; Moog, E.; Shaw, S. Simulation, design and validation of a UAV SOFC propulsion system. IEEE Trans. Aerosp. Electron. Syst. 2009. [CrossRef]

24. Stepaniak, M.; Van Graas, F.; De Haag, M. Design of an electric propulsion system for a quadrotor unmanned aerial vehicle. J. Aircr. 2009, 46, 1050-1058. [CrossRef]

25. Soban, D.; Upton, E. Design of a UAV to Optimize Use of Fuel Cell Propulsion Technology; American Institute of Aeronautics and Astronautics Inc.: Reston, VA, USA, 2005; Volume 4, pp. 2075-2089. [CrossRef]

26. Ahn, J.M.; Son, J.C.; Lim, D.K. Optimal Design of Outer-Rotor Surface Mounted Permanent Magnet Synchronous Motor for Cogging Torque Reduction Using Territory Particle Swarm Optimization. J. Electr. Eng. Technol. 2021, 16, 429-436. [CrossRef]

27. Zhang, H.; Song, B.; Li, F.; Xuan, J. Multidisciplinary design optimization of an electric propulsion system of a hybrid UAV considering wind disturbance rejection capability in the quadrotor mode. Aerosp. Sci. Technol. 2021, 110. [CrossRef]

28. Thilakraj, M.; Ravi, V.; Charkravarthy, K. Design optimization of rotor propulsive delta wing. Int. J. Mech. Prod. Eng. Res. Dev. 2019, 9, 887-896. [CrossRef]

29. Anastasopoulos, L.; Hornung, M. Design of a Real-Time Test Bench for UAV Servo Actuators; American Institute of Aeronautics and Astronautics Inc.: Reston, VA, USA, 2018. [CrossRef]

30. Yazdani-Asrami, M.; Alipour, M.; Gholamian, S. Optimal ECO-design of permanent magnet Brushless DC motor using modified tabu search optimizer and finite element analysis. J. Magn. 2015, 20, 161-165. [CrossRef]

31. Ullah, S.; Khan, Q.; Mehmood, A.; Kirmani, S.; Mechali, O. Neuro-adaptive fast integral terminal sliding mode control design with variable gain robust exact differentiator for under-actuated quadcopter UAV. ISA Trans. 2021. [CrossRef]

32. Abro, G.; Asirvadam, V.; Bin Mohd Zulkifli, S.; Sattar, A.; Kumar, D.; Anwer, A. Effects of unmodelled dynamic factors on an under-actuated quadrotor: A review of hybrid observer design methods. Meas. Control. 2020, 53, 1978-1987. [CrossRef]

33. Pavkovic, D.; Krznar, M.; Cipek, M.; Zorc, D.; Trstenjak, M. Internal Combustion Engine Control System Design Suitable for Hybrid Propulsion Applications; Institute of Electrical and Electronics Engineers Inc.: New York, NY, USA, 2020; pp. 1614-1619. [CrossRef]

34. Ullah, S.; Mehmood, A.; Khan, Q.; Rehman, S.; Iqbal, J. Robust Integral Sliding Mode Control Design for Stability Enhancement of Under-actuated Quadcopter. Int. J. Control. Autom. Syst. 2020, 18, 1671-1678. [CrossRef]

35. Van Treuren, K.; Sanchez, R.; Wisniewski, C.; Leitch, P. Investigation of Aeroacoustics and Motor Efficiency of a Two-Bladed Stock and Five-Bladed Propeller Designs for Static Quadcopter Applications; American Institute of Aeronautics and Astronautics Inc.: Reston, VA, USA, 2020; pp. 1-20. [CrossRef]

36. Yang, T.; Wang, S.; Yang, J. Design of High-Power Dual-Redundancy Electro-Mechanical Actuator for Scout and Strike UAV; Institute of Physics Publishing: Bristol, UK, 2020; Volume 790. [CrossRef]

37. Cheng, P.; Cai, C.; Zou, Y. Finite Time Fault Tolerant Control Design for UAV Attitude Control Systems with Actuator Fault and Actuator Saturation; Elsevier B.V.: Amsterdam, The Netherlands, 2019; Volume 52, pp. 53-58. [CrossRef]

38. Dai, X.; Quan, Q.; Ren, J.; Cai, K.Y. An analytical design-optimization method for electric propulsion systems of multicopter UAVs with desired hovering endurance. IEEE/ASME Trans. Mechatronics 2019, 24, 228-239. [CrossRef]

39. Gebauer, J.; Wagnerová, R.; Smutný, P.; Podešva, P. Controller Design for Variable Pitch Propeller Propulsion Drive; Elsevier B.V.: Amsterdam, The Netherlands, 2019; Volume 52, pp. 186-191. [CrossRef]

40. Jims John Wessley, G. Design and modeling of a micro turbojet engine for UAV propulsion. Int. J. Eng. Adv. Technol. 2019, 8, 722-726.

41. Kasem, A.; Gamal, A.; Hany, A.; Gaballa, H.; Ahmed, K.; Romany, M.; Abdelkawy, M.; Abdelrahman, M. Design and implementation of an unmanned aerial vehicle with self-propulsive wing. Adv. Mech. Eng. 2019, 11. [CrossRef]

42. Lee, H.S.; Cha, H.R.; Yang, S.H.; Kim, D.H.; Lee, G.S.; Kim, H.W. Optimal Design and Analysis of Interior Permanent Magnet Motor for High-Thrust Drone; Institute of Electrical and Electronics Engineers Inc.: New York, NY, USA, 2019. [CrossRef]

43. Mallavalli, S.; Fekih, A. A Fault Tolerant Control Design for Actuator Fault Mitigation in Quadrotor UAVS; Institute of Electrical and Electronics Engineers Inc.: New York, NY, USA, 2019; pp. 5111-5116. [CrossRef]

44. Nigro, M.; Pierri, F.; Caccavale, F. Preliminary Design, Modeling and Control of a Fully Actuated Quadrotor UAV; Institute of Electrical and Electronics Engineers Inc.: New York, NY, USA, 2019; pp. 1108-1116. [CrossRef] 
45. Oukassi, S.; Poncet, S.; Frutos, J.; Salot, R. Design, Microfabrication and Characterization of Free form Factor, Lightweight thin Film Battery for Powering Bioinspired Nano-Drones Based on MEMS Actuation; Institute of Physics Publishing: Bristol, UK, 2019; Volume 1407. [CrossRef]

46. Wang, S.; Song, B.; He, L.; Lang, X. Modeling and Robust Attitude Controller Design of a Distributed Propulsion Tilt-Wing UAV in Hovering Flight; Institute of Electrical and Electronics Engineers Inc.: New York, NY, USA, 2019; pp. 1480-1485. [CrossRef]

47. Wang, S.; Song, B.; He, L. Robust Attitude Control System Design for a Distributed Propulsion Tilt-Wing UAV in Flight State Transition. In Asia-Pacific International Symposium on Aerospace Technology; Springer: Singapore, 2018; pp. 2368-2387. [CrossRef]

48. Zhang, Z.; Ma, T.; Hao, S.; Wang, Z.; Liu, Y. Design of A Distributed Propulsion VTOL UAV; Institute of Electrical and Electronics Engineers Inc.: New York, NY, USA, 2019; pp. 84-89. [CrossRef]

49. Franz-Michael, S.; Philipp, S.; Christian, R.; Mirko, H. Design and Testing of an Electric Actuated Airbrake for Dynamic Airspeed Control of an Unmanned Aeroelastic Research Vehicle; American Institute of Aeronautics and Astronautics Inc.: Reston, VA, USA, 2018. [CrossRef]

50. Shavin, M. Design and identification of tilt-motor quadrotor control system. EDP Sci. 2018, 211. [CrossRef]

51. He, Y.; Woolston, M.; Perreault, D. Design and Implementation of a Lightweight High-Voltage Power Converter for Electro-Aerodynamic Propulsion; Institute of Electrical and Electronics Engineers Inc.: New York, NY, USA, 2017; [CrossRef]

52. Kimaru, J.; Bouferrouk, A. Design, Manufacture and Test of a Camber Morphing Wing Using MFC Actuated Mart rib; Institute of Electrical and Electronics Engineers Inc.: New York, NY, USA, 2017; pp. 791-796. [CrossRef]

53. Lu, W.; Zhang, D.; Zhang, J.; Li, T.; Hu, T. Design and Implementation of a Gasoline-Electric Hybrid Propulsion System for a Micro Triple Tilt-Rotor VTOL UAV; Institute of Electrical and Electronics Engineers Inc.: New York, NY, USA, 2017; pp. 433-438. [CrossRef]

54. Qian, M.; Gao, Z. Adaptive Fault Tolerant Control Design for UAV with Multiple Actuator Faults; Institute of Electrical and Electronics Engineers Inc.: New York, NY, USA, 2017; pp. 814-819. [CrossRef]

55. Qian, M.; Xiong, K.; Gao, Z.; Lin, J. T-S fuzzy Model-Based adaptive controller design for UAV with actuator saturation. ICIC Express Lett. 2017, 11, 221-230.

56. Yu, X.; Li, P.; Zhang, Y. Fault-tolerant control design against actuator faults with application to UAV formation flight. IEEE Comput. Soc. 2017, 7167-7171. [CrossRef]

57. Bondyra, A.; Gardecki, S.; Gasior, P.; Giernacki, W. Performance of coaxial propulsion in design of multi-rotor UAVs. Adv. Intell. Syst. Comput. 2016, 440, 523-531. [CrossRef]

58. Giernacki, W. Near to Optimal Design of PID Fractional-Order Speed Controller (FOPID) for Multirotor Motor-Rotor Simplified Model; Institute of Electrical and Electronics Engineers Inc.: New York, NY, USA, 2016; pp. 320-326. [CrossRef]

59. Kawai, Y.; Uchiyama, K. Design of Frequency Shaped LQR Considering Dynamic Characteristics of the Actuator; Institute of Electrical and Electronics Engineers Inc.: New York, NY, USA, 2016; pp. 1235-1239. [CrossRef]

60. Li, Y.; Xiang, S.; Wang, S.; Huang, J.; Zhao, Y.; Guo, J. Research on Optimization Design of UAV Main Propulsion Motor Based on Particle Swarm Optimization Algorithm; Institute of Electrical and Electronics Engineers Inc.: New York, NY, USA, 2016; pp. $2472-2476$. [CrossRef]

61. Ortiz-Torres, G.; López-Estrada, F.; Reyes-Reyes, J.; García-Beltrán, C.; Theilliol, D. An Actuator Fault Detection and Isolation method design for Planar Vertical Take-off and Landing Unmanned Aerial Vehicle modelled as a qLPV system. IFAC Pap. 2016, 49, 272-277. [CrossRef]

62. Qi, X.; Qi, J.; Theilliol, D.; Song, D.; Zhang, Y.; Han, J. Self-Healing Control Design under Actuator Fault Occurrence on Single-rotor Unmanned Helicopters. J. Intell. Robot. Syst. Theory Appl. 2016, 84, 21-35. [CrossRef]

63. Grannan, N.; Gutmark, E. An Off-Design Analysis of an Inverse Brayton Cycle Based UAV Propulsion System; American Institute of Aeronautics and Astronautics Inc.: Reston, VA, USA, 2015. [CrossRef]

64. Theilliol, D.; Weber, P.; Chamseddine, A.; Zhang, Y. Optimization-Based Reliable Control Allocation Design for Over-Actuated Systems; Institute of Electrical and Electronics Engineers Inc.: New York, NY, USA, 2015; pp. 1225-1230. [CrossRef]

65. Wasik, M.; Skarka, W. Design Optimization of Electric Propulsion of Flying Exploratory Autonomous Robot; IOS Press BV: Amsterdam, The Netherlands, 2015; Volume 2, pp. 367-376. [CrossRef]

66. Xu, Q.; Yang, H.; Jiang, B.; Zhou, D.; Zhang, Y. Adaptive fault-tolerant control design for UAVs formation flight under actuator faults. In Proceedings of the 2013 International Conference on Unmanned Aircraft Systems (ICUAS), Atlanta, GA, USA, 28-31 May 2013; pp. 1097-1105. [CrossRef]

67. Gao, Z.; Qian, M.; Yin, J.; Lin, J.; He, H. Fault tolerant control design for hypersonic UAV attitude dynamical systems with actuator faults. ICIC Express Lett. Part B Appl. 2012, 3, 1293-1301.

68. Hung, J.C.; Gonzalez, L. Design, simulation and analysis of a parallel hybrid electric propulsion system for unmanned aerial vehicles. Prog. Aerosp. Sci. 2012, 4, 2655-2661.

69. Koster, J.; Balaban, S.; Hillery, D.; Humbargar, C.; Nasso, D.; Serani, E.; Velazco, A. Design of a blended wing body UAS with hybrid propulsion. Am. Soc. Mech. Eng. 2011, 1, 331-337. [CrossRef]

70. Yu, K.; Guo, H.; Wang, D.; Li, L. Design of multi-redundancy electro-mechanical actuator controller with DSP and FPGA. In Proceedings of the 2007 International Conference on Electrical Machines and Systems (ICEMS), Seoul, Korea, 8-11 October 2007; pp. 584-587. [CrossRef] 
71. Tang, L.; Kacprzynski, G.; Roemer, M.; Vachtsevanos, G.; Patterson-Hine, A. Automated Contingency Management Design for Advanced Propulsion Systems; American Institute of Aeronautics and Astronautics Inc.: Reston, VA, USA, 2005; Volume 2, pp. 878-886. [CrossRef]

72. Chew, F.; Gan, S.; Hesse, H. Rapid Design Process of Shrouded Rotors for Efficient UAV Propulsion; American Institute of Aeronautics and Astronautics Inc.: Reston, VA, USA, 2021; pp. 1-19. [CrossRef]

73. Hossain, A. Conceptual design of a low-Cost linear actuator for variable span wing application. INCAS Bull. 2021, 13, 69-76. [CrossRef]

74. Liben, M.; Ludois, D. Analytical Design and Experimental Testing of a Self-Cooled, Toroidally Wound Ring Motor with Integrated Propeller for Electric Rotorcraft. IEEE Trans. Ind. Appl. 2021. [CrossRef]

75. Zhao, A.; Zhang, J.; Li, K.; Wen, D. Design and implementation of an innovative airborne electric propulsion measure system of fixed-wing UAV. Aerosp. Sci. Technol. 2021, 109. [CrossRef]

76. Duan, D.; Wang, Z.; Wang, Q.; Li, J. Research on integrated optimization design method of high-efficiency motor propeller system for UAVs with multi-states. IEEE Access 2020, 8, 165432-165443. [CrossRef]

77. Liu, Z.; Theilliol, D.; Yang, L.; He, Y.; Han, J. Interconnection and Damping Assignment Passivity-Based Control Design Under Loss of Actuator Effectiveness. J. Intell. Robot. Syst. Theory Appl. 2020, 100, 29-45. [CrossRef]

78. Marcolini, F.; De Donato, G.; Giulii Capponi, F.; Incurvati, M.; Caricchi, F. Design of a Multiphase Coreless Axial Flux Permanent Magnet Machine for Unmanned Aerial Vehicle Propulsion; Institute of Electrical and Electronics Engineers Inc.: New York, NY, USA, 2020; pp. 1756-1763. [CrossRef]

79. Ren, X.L. Observer Design for Actuator Failure of a Quadrotor. IEEE Access 2020, 8, 152742-152750. [CrossRef]

80. Anzai, T.; Zhao, M.; Murooka, M.; Shi, F.; Okada, K.; Inaba, M. Design, Modeling and Control of Fully Actuated 2D Transformable Aerial Robot with 1 DoF Thrust Vectorable Link Module; Institute of Electrical and Electronics Engineers Inc.: New York, NY, USA, 2019; pp. 2820-2826. [CrossRef]

81. Dai, W.; Li, W.; Wan, F. Dual Redundancy Design of Brushless DC Motor for UAV Steering Gear; Institute of Electrical and Electronics Engineers Inc.: New York, NY, USA, 2019; pp. 279-283. [CrossRef]

82. Guan, W.; Shi, P. Design of Fault Tolerant Control System for Four-Rotor UAV Actuator Failure; Institute of Electrical and Electronics Engineers Inc.: New York, NY, USA, 2019; pp. 3927-3932. [CrossRef]

83. Guiatni, M.; Saidani, H.; Bouzid, Y. Fault Tolerant Control Design for Actuator Loss of Effectiveness in Quadrotor Uavs; Institute of Electrical and Electronics Engineers Inc.: New York, NY, USA, 2019; [CrossRef]

84. Liben, M.; Ludois, D. Analytical Design of an Easily Manufacturable, Air-Cooled, Toroidally Wound Permanent Magnet Ring Motor with Integrated Propeller for Electric Rotorcraft; Institute of Electrical and Electronics Engineers Inc.: New York, NY, USA, 2019; pp. 4483-4490. [CrossRef]

85. Priatmoko, M.; Nirbito, W. Design Analysis of Ducted Propeller for Bicopter Drone Propulsion; Institute of Physics Publishing: Bristol, UK, 2019; Volume 685. [CrossRef]

86. Qian, M.; Zhai, L.; Zhong, G.; Gao, Z. Adaptive Backstepping Fault Tolerant Controller Design for UAV with Multiple Actuator Faults; Institute of Electrical and Electronics Engineers Inc.: New York, NY, USA, 2019; pp. 682-688. [CrossRef]

87. De Simone, M.; Guida, D. Control design for an under-actuated UAV model. FME Trans. 2018, 46, 443-452. [CrossRef]

88. Kang, Y.; Lim, B.; Rhee, D.; Jun, S.; Park, T.; Lee, Y.; Jun, Y. Design of turbo-compression system for Hale UAV propulsion system. Am. Soc. Mech. Eng. 2018, 2. [CrossRef]

89. Liu, B.; Jiao, Z. LQR Lateral-Directional Control Law Design for Distributed Propulsion Layout Flying Wing; Institute of Electrical and Electronics Engineers Inc.: New York, NY, USA, 2018; pp. 715-719. [CrossRef]

90. Mallavalli, S.; Fekih, A. Adaptive Fault Tolerant Control Design for Actuator Fault Mitigation in Quadrotor UAVs; Institute of Electrical and Electronics Engineers Inc.: New York, NY, USA, 2018; pp. 193-198. [CrossRef]

91. Xu, X.; Deng, Y. UAV Power Component-DC Brushless Motor Design with Merging Adjacent-Disturbances and IntegratedDispatching Pigeon-Inspired Optimization. IEEE Trans. Magn. 2018, 54. [CrossRef]

92. Bougas, L.; Rößler, C.; Hornung, M. Design and Experimental Validation of a Propulsion Duct for a Jet Propelled Low Observable Scaled UAV Demonstrator; American Institute of Aeronautics and Astronautics Inc.: Reston, VA, USA, 2017. [CrossRef]

93. Gong, A.; Verstraete, D. Design and Bench Test of a Fuel-Cell/Battery Hybrid UAV Propulsion System Using Metal Hydride Hydrogen Storage; American Institute of Aeronautics and Astronautics Inc.: Reston, VA, USA, 2017.

94. Kamaruzaman, N.; Abdullah, E. Design and Testing of Shape Memory Alloy Actuation Mechanism for Flapping Wing Micro Unmanned Aerial Vehicles; Institute of Physics Publishing: Bristol, UK, 2017; Volume 270. [CrossRef]

95. Kochersberger, K.; Ohanian, O.J.I.; Probst, T.; Gelhausen, P. Design and flight test of the generic micro-aerial vehicle (GenMAV) utilizing piezoelectric conformal flight control actuation. J. Intell. Mater. Syst. Struct. 2017, 28, 2793-2809. [CrossRef]

96. Zhu, M.; Xia, L.; Hu, Y.; Chen, J.; Song, X. Design of Compact Smart Actuator; Institute of Electrical and Electronics Engineers Inc.: New York, NY, USA, 2017. [CrossRef]

97. Muehlebach, M.; D'Andrea, R. The Flying Platform-A testbed for ducted fan actuation and control design. Mechatronics 2017, 42, 52-68. [CrossRef]

98. Parvez Alam, P.; Manoharan, D.; Chandramohan, S.; Chakkath, S.; Maurya, S. Design, Development \& Testing of Test Rig Setup for UAV Propulsion System. SAE Tech. Pap. 2017, 2017. [CrossRef] 
99. Zhu, M.; Xia, L.; Hu, Y.; Zhang, W.; Ji, D.; Song, X. Air cooling analysis and design of impacted flexible actuator's servo controller based on PLECS. EDP Sci. 2017, 108. [CrossRef]

100. Zulkipli, A.; Raj, T.; Hashim, F.; Huddin, A. Characterization of DC Brushless Motor for an Efficient Multicopter Design; Institute of Electrical and Electronics Engineers Inc.: New York, NY, USA, 2017; pp. 586-591. [CrossRef]

101. Chu, W.; Guo, H.; Xing, W. Design of Non-Similar Dual-Redundant Electromechanical Actuation System for UAV Landing Gear; Institute of Electrical and Electronics Engineers Inc.: New York, NY, USA, 2016; pp. 592-595. [CrossRef]

102. Qian, M.S.; Jiang, B.; Liu, H.T. Dynamic surface active fault tolerant control design for the attitude control systems of UAV with actuator fault. Int. J. Control. Autom. Syst. 2016, 14, 723-732. [CrossRef]

103. Valencia, E.; Benalcazar, M.; Saá, J.; Magne, N.; Hidalgo, V. Design Point Analysis of a Distributed Propulsion System with Boundary Layer Ingestion Implemented in UAVs for Agriculture in the Andean Region; American Institute of Aeronautics and Astronautics Inc.: Reston, VA, USA, 2016; [CrossRef]

104. Bryner, E.; Ransom, D.; Bishop, J.; Coogan, S.; Musgrove, G. Design of a small scale gas turbine for a hybrid propulsion system. Am. Soc. Mech. Eng. 2015, 8. [CrossRef]

105. Chamseddine, A.; Theilliol, D.; Zhang, Y.; Join, C.; Rabbath, C. Active fault-tolerant control system design with trajectory re-planning against actuator faults and saturation: Application to a quadrotor unmanned aerial vehicle. Int. J. Adapt. Control. Signal Process. 2015, 29, 1-23. [CrossRef]

106. Khamlia, M.; Bennaceur, S.; Azouz, N.; Samaali, S.; Abichou, A.; Lerbet, J. Modeling and actuators design of an unconventional airship. Am. Soc. Mech. Eng. 2015, 57397, V04AT04A018. [CrossRef]

107. Bahoura, M.; Williams, F.; Myers, O.; Plastied, B.; Hall, A.; Riddick, J. Design and fabrication of a functionally modified bimorph actuator. Am. Soc. Mech. Eng. 2014, 2. [CrossRef]

108. Chamseddine, A.; Theilliol, D.; Sadeghzadeh, I.; Zhang, Y.; Weber, P. Optimal reliability design for over-actuated systems based on the MIT rule: Application to an octocopter helicopter testbed. Reliab. Eng. Syst. Saf. 2014, 132, 196-206. [CrossRef]

109. Jackson, T.; Livne, E. Integrated aeroservoelastic design optimization of actively controlled strain-actuated flight vehicles. AIAA J. 2014, 52, 1105-1123. [CrossRef]

110. Marimuthu, N.; Abdullah, E.; Majid, D.; Romli, F. Conceptual design of flapping wing using shape memory alloy actuator for micro unmanned aerial vehicle. Appl. Mech. Mater. 2014, 629, 152-157. [CrossRef]

111. Prazenica, R.; Kim, D.; Moncayo, H.; Azizi, B.; Chan, M. Design, characterization, and testing of macro-fiber composite actuators for integration on a fixed-wing UAV. SPIE 2014, 9057. [CrossRef]

112. Bogusz, P.; Korkosz, M.; Prokop, J. A study of design process of BLDC motor for aircraft hybrid drive. In Proceedings of the 2011 IEEE International Symposium on Industrial Electronics, Gdansk, Poland, 27-30 June 2011; pp. 508-513. [CrossRef]

113. Dönmez, B.; Özkan, B. Design of an antagonistic shape memory alloy actuator for flap type control surfaces. Int. Soc. Opt. Photonics 2011, 7977. [CrossRef]

114. Dönmez, B.; Özkan, B. Design and control of a shape memory alloy actuator for flap type aerodynamic surfaces. IFAC Secr. 2011, 44, 8138-8143. [CrossRef]

115. Lieh, J.; Spahr, E.; Behbahani, A.; Hoying, J. Design of Hybrid Propulsion Systems for Unmanned Aerial Vehicles; American Institute of Aeronautics and Astronautics Inc.: Reston, VA, USA, 2011. [CrossRef]

116. Yu, K.; Guo, H.; Xing, W.; Xu, J. Controller design and implementation for double-stator tri-redundant brushless DC motor based on DSP and FPGA. In Proceedings of the 2011 International Conference on Electrical Machines and Systems, Beijing, China, 20-23 August 2011. [CrossRef]

117. Sofla, A.; Meguid, S.; Tan, K. Novel morphing wing design using antagonistic shape memory alloy actuation. ASME Int. Mech. Eng. Congr. Expo. 2010, 1, 33-36. [CrossRef]

118. Barrett, R.; McMurtry, R.; Vos, R.; Tiso, P.; De Breuker, R. Post-buckled precompressed piezoelectric flight control actuator design, development and demonstration. Smart Mater. Struct. 2006, 15, 1323-1331. [CrossRef]

119. Engeda, A. Development of a design methodoloy for ducted fan systems used in micro unmanned air vechile propulsion. Turbo Expo Power Land Sea Air 2006, 429-438. [CrossRef]

120. Yoon, K.; Setiawan, H.; Goo, N. Design of elevator control surface actuated by LIPCA for small unmanned air vehicle. Int. Soc. Opt. Photonics 2006, 6173. [CrossRef]

121. Lim, S.; Lee, S.; Park, H.; Yoon, K.; Goo, N. Design and demonstration of a biomimetic wing section using a lightweight piezo-composite actuator (LIPCA). Smart Mater. Struct. 2005, 14, 496-503. [CrossRef]

122. Manzo, J.; Garcia, E.; Wickenheiser, A.; Horner, G. Design of a shape-memory alloy actuated macro-scale morphing aircraft mechanism. Int. Soc. Opt. Photonics 2005, 5764, 232-240. [CrossRef]

123. Rajashekar, S.; Venkatesh, C.; Singh, P. Design of linear electro-mechanical actuator for an unmanned air vehicle. In Proceedings of the National Conference on Machines and Mechanisms, NaCoMM 2005, North Guwahati, India, 16-17 December 2005; pp. 159-164.

124. Collie, W.; Burgun, R.; Heinzen, S.; Hall, C., Jr.; Chokani, N. Advanced propulsion system design and integration for a turbojet powered unmanned aerial vehicle. In Proceedings of the 41st Aerospace Sciences Meeting and Exhibit, Reno, NV, USA, 6-9 January 2003.

125. Ehrlich, H.; Kurz, K.H.; Rued, K.P.; Lauer, W. Trends in Military Aeroengine-Design-From EJ200 to Future Manned and Unmanned Vehicle Propulsion; American Institute of Aeronautics and Astronautics Inc.: Reston, VA, USA, 2003. 
126. Lim, S.; Lee, S.; Park, H.; Yoon, K.; Goo, N. Design and demonstration of a biomimetic wing section using Lightweight Piezoceramic Composite Actuator (LIPCA). Smart Mater. Struct. 2003, 5056, 142-150. [CrossRef]

127. Amici, C.; Pellegrini, N.; Tiboni, M. The Robot Selection Problem for Mini-Parallel Kinematic Machines: A Task-Driven Approach to the Selection Attributes Identification. Micromachines 2020, 11, 711. [CrossRef] [PubMed]

128. Boukoberine, M.N.; Zhou, Z.; Benbouzid, M. A critical review on unmanned aerial vehicles power supply and energy management: Solutions, strategies, and prospects. Appl. Energy 2019, 255, 113823. [CrossRef]

129. Yezeguelian, A.; Isikveren, A.T. Methods to improve UAV performance using hybrid-electric architectures. Aircr. Eng. Aerosp. Technol. 2020, 92, 685-700. [CrossRef]

130. Kidd, T.; Yu, Z.; Dobbs, S.; Anderson, K.R.; Oetting, G.; Kim, J.; O'Connell, M. UAV Power Management, Generation, and Storage System Principles and Design. In Proceedings of the 2020 IEEE Conference on Technologies for Sustainability (SusTech), Santa Ana, CA, USA, 23-25 April 2020; pp. 1-8. [CrossRef]

131. Dobbs, S.; Yu, Z.; Anderson, K.R.; Franco, J.A.; Deravanessian, A.E.; Lin, A.; Ahn, A. Design of an Inflight Power Generation and Storage System for Use in UAVs. In Proceedings of the 2018 IEEE Conference on Technologies for Sustainability (SusTech), Long Beach, CA, USA, 11-13 November 2018; pp. 1-8. [CrossRef]

132. Kim, S.A. Design and characteristic analysis of motor considering propeller structure of integrated propulsor for underwater drone. Trans. Korean Inst. Electr. Eng. 2020, 69, 1010-1015. [CrossRef]

133. Rajappa, S.; Ryll, M.; Bulthoff, H.; Franchi, A. Modeling, Control and Design Optimization for a Fully-Actuated Hexarotor Aerial Vehicle with Tilted Propellers; Institute of Electrical and Electronics Engineers Inc.: New York, NY, USA, 2015; pp. 4006-4013. [CrossRef]

134. Ampatis, C.; Papadopoulos, E. Parametric Design and Optimization of Multi-Rotor Aerial Vehicles; Springer: Cham, Switzerland, 2014; Volume 91, pp. 1-25. [CrossRef] 